ENGINEERING DATA TRANSMITTAL

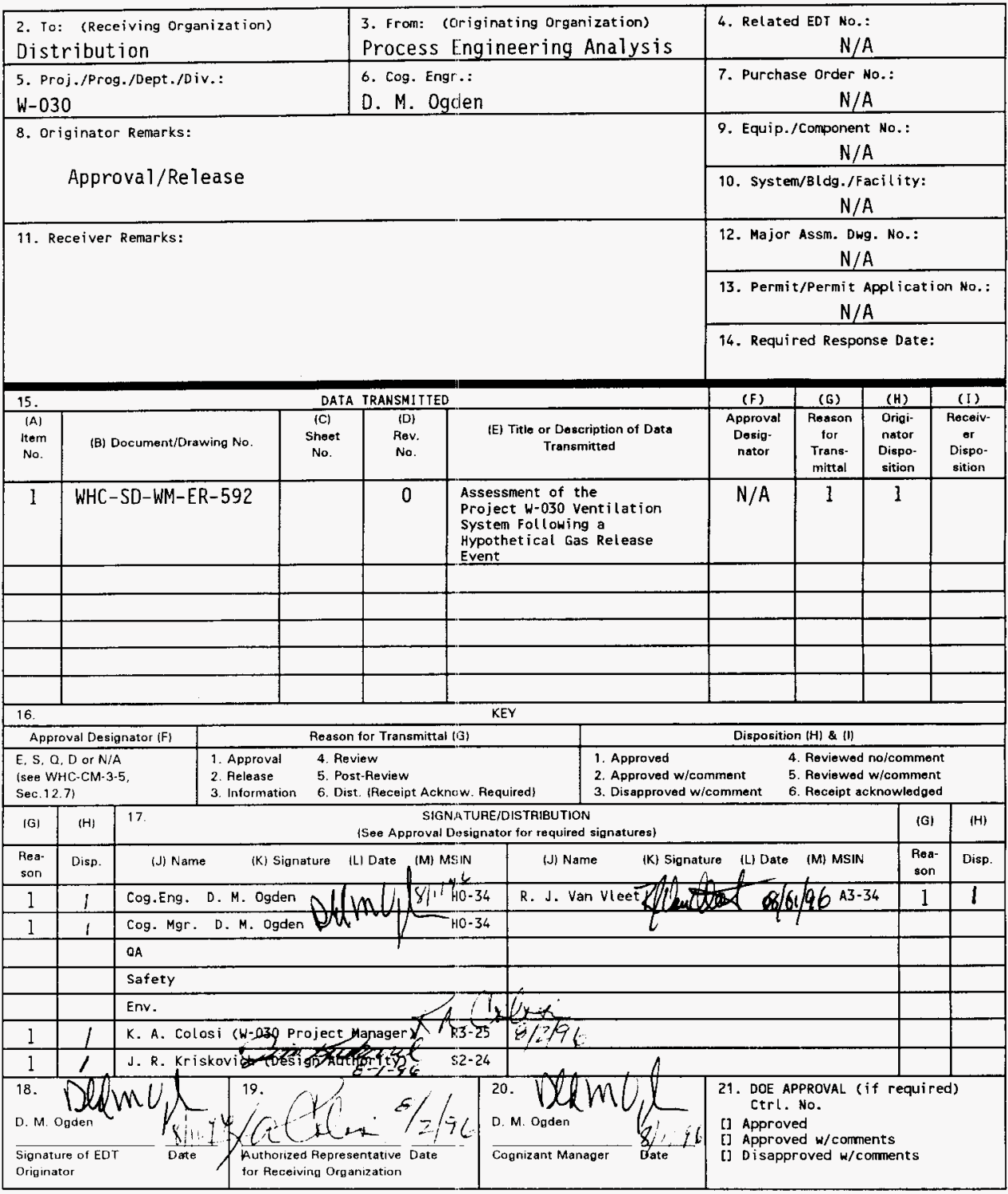




\section{Assessment of the Project W-030 Ventilation System Following a Hypothetical Gas Release Event}

D. M. Ogden

Westinghouse Hanford Company, Richland, WA 99352

U.S. Department of Energy Contract DE-AC06-87RL10930

\begin{tabular}{|c|c|c|}
\hline $\begin{array}{l}\text { DT/ECN: } \\
\text { rg Code: } \\
\text { \& Code: }\end{array}$ & $\begin{array}{l}614686 \\
74 A 50 \\
\text { EW3135040 }\end{array}$ & $\begin{array}{l}\text { UC: } 2020 \\
\text { Charge Code: } \\
\text { Total Pages: }\end{array}$ \\
\hline
\end{tabular}

Key Words: Hydrogen Concentration, Gas Release Event, Tank Ventilation System, GOTH, Hydraulic Analysis

Abstract: The purpose of this evaluation was to determine the potential for hydrogen concentrations exceeding the allowable 1 imits at spark sources within the $\mathrm{W}-030$ ventilation system following a hypothetical gas release event (GRE) in tank 241-AY-101.

IRADEMARK DISCLAIMER. Reference herein :o any specific commercial product, process, or service by trade name, trademark, manufacturer, or ctherwise, does not necessarily constitute or imply its endorsement, recommendation, or favoring by the United States Government or any agency thereof or its contractors or subcontractors.

Printed in the United States of America. To obtain copies of this document, contact: WHC/BCS Document Control Services, P.O. Box 1970, Mailstop H6-08, Richland WA 99352, Phone (509) 372-2420; Fax (509) 376-4989.
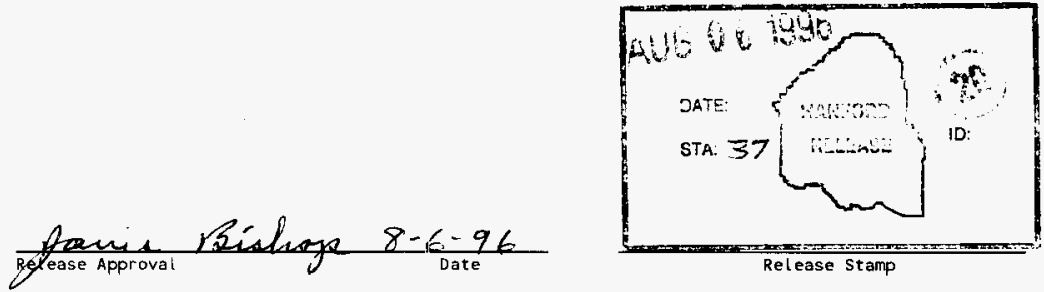

Approved for Public Release 


\title{
Assessment of the Project W-030 Ventilation System Following a Hypothetical Gas Release Event
}

\author{
Prepared by \\ B. C. Fryer \\ M. J. Thurgood \\ John Marvin, inc. \\ for Westinghouse Hanford Company \\ C. M. Ogden \\ Westinghouse Hanford Company
}

July 1996

Issued by

WESTINGHOUSE HANFORD COMPANY

for the

U.S. DEPARTMENT OF ENERGY

RICHLAND OPERATIONS OFFICE

RICHLAND, WASHINGTON 


\section{CONTENTS}

1.0 INTRODUCTION ....................... 1-1

2.0 METHODOLOGY ........................ 2-1

3.0 ASSUMPTIONS, INPUT AND BASES FOR THE ANALYSIS . . . . . . . . . . . 3-1

3.1 SYSTEM DESCRIPTION . . . . . . . . . . . . . . . . 3-1

3.2 ICF KAISER ENGINEERS DESIGN AND OPERATING BASIS ........ .1

3.3 WHC MODIFICATIONS OF THE OPERATING CONDITIONS BASED ON VENDOR

SUPPLIED RECIRCULATION FAN . . . . . . . . . . . . . . 3-1

3.4 CONTROL SYSTEM OPERATION . . . . . . . . . . . . . . . . . . . 3-2

3.5 PIPING GEOMETRY . . . . . . . . . . . . . . . . . . . 3-2

3.6 DE-ENERGIZING TANK 241-AY-101 RECIRCULATION SYSTEM . . . . . 3-11

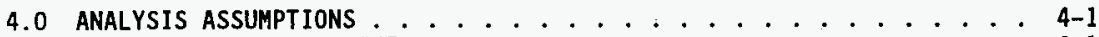

4.1 GAS RELEASE EVENT . . . . . . . . . . . . . . . . . . . . 4-1

4.1.1 Maximum Pressurization GRE . . . . . . . . . . . 4-1

4.1.2 Conservative GRE .................. . . 4-1

4.1.3 Maximum Bounding GRE .................. 4-2

4.2 CONTROL SYSTEM OPERATION DURING GRE . . . . . . . . . . 4-2

5.0 RESULTS OF THE EVALUATION . . . . . . . . . . . . . . . . . . . 5-1

5.1 MAXIMUM PRESSURIZATION AND FLOW ANALYSES .......... .1

5.2 CONSERVATIVE GRE ANALYSES ................... . . 5-1

5.3 MAXIMUM BOUNDING GRE ANALYSES ............... . . 5-2

6.0 CONCLUSIONS ......................... 6-1

7.0 REFERENCES ........................ 7-1

\section{LIS"' OF FIGURES}

2-1. GOTH Computer Model ...................... 2-2

3-1. Tank Farm 241-AY/AZ and W-030 Ventilation System Piping . . . . . 3-3

3-2a. Tanks 241-AY/AZ W-030 Recirculation and

Primary Ventilation System Schematic . . . . . . . . . . . . 3-4

3-2b. Proposed W-030 Ventilation System Configuration . . . . . . . . 3-5

3-3. Tank Farm 241-AY/AZ and W-030 Ventilation System Piping Showing ICF Kaiser Section/Junction Numbering System . . . . . . . . 3-6

3-4. Recirculation Fan Characteristics . . . . . . . . . . . . 3-9

4-1a. Normalized Hypothetical Release History . . . . . . . . . . . . . 4-3

4-1b. Gas Release Events Assumed . . . . . . . . . . . . . . . . . . 4-4 
5-1. Pressure Within Tank 241-AY-101 and its Recirculation Systems . . 5-3

5-2. Flows Within Tank 241-AY-101. Recirculation System and Bleed Flow to Primary System . . . . . . . . . . . . . . 5-4

5-3. Flow Through Tanks Bleed Flow Control Valves........... . 5-5

5-4. Pressures Downstream of Flow Control Valves and Upstream of Primary Exhaust Fan Inlet . . . . . . . . . . . . . . 5-6

5-5. Tanks Dome Pressures . . . . . . . . . . . . . . . . . 5-7

5-6. Flow in Primary System Manifold Piping . . . . . . . . . . . . 5-8

5-7. Pressures Within Tank 241-AY-101 and its Recirculation Systems . . 5-9

5-8. Flows Within Tank 241-AY-101 Recirculation System and Bleed Flow to Primary System . . . . . . . . . . . . . . 5-10

5-9. Flow Through Tanks Bleed Flow Control Valves ........... 5-11

5-10. Pressures Downstream of Flow Control Valves and Upstream of Primary Exhaust Fan Inlet . . . . . . . . . . 5-12

5-11. Tanks Dome Pressures . . . . . . . . . . . . . . . . . 5-13

5-12. Flow in Primary System Manifold Piping . . . . . . . . . . 5-14

5-13. Hydrogen Concentrations for Conservative GRE . . . . . . . . . . . 5-15

5-14. Hydrogen Concentrations for Maximum Bounding GRE . . . . . . . . 5-16

5-15. Flow Through Tanks Bleed Flow Control Valves

for the Maximum Bounding GRE ................ . 5-17

\section{LIST OF TABLES}

3-1. ICF Kaiser Normal/Design Operating Pressure Drop and Pressures . . 3-7

3-2. WHC Modified Norma1/Design Operating Pressure Drops and Pressure . 3-8

3-3. W-030 Tank Inlet, Recirculation, and Primary Ventilation System Piping--Based on Coordinate Calculated Lengths . . . . . . . 3-10

\section{APPENDIX}

APPENDIX A. LETTER REPORT 23230-93-SAW-001 . . . . . . . . . . . . A-1 
WHC-SD-WM-ER-592, Rev. 0

\section{ASSESSMENT OF THE PROJECT W-03O VENTILATION SYSTEM FOLLOWING A HYPOTHETICAL GAS RELEASE EVENT}

\subsection{INTRODUCTION}

A flammable gas screening of the 177 waste tanks was recently completed (Hodgson 1996). The screening was performed using a barometric pressure method to estimate the trapped gas volume in the waste. The estimated gas volumes were based on very conservative assumptions and were intended to provide a conservative upper bound for the volume of trapped gas at tank bottom pressure. Tank 241-AY-101 was estimated to contain $3313 \mathrm{ft}^{3}$ of trapped gas. Efforts are under way to provide improved tank waste level data to remove unnecessary conservatism and improve the gas volume estimate. However, a potential for a spontaneous Gas Release Event (GRE) may exist for tank 24lAY-101. As a result of the flammable gas screening, the safety of the operation of the Project $W-030$ ventilation system in a potential flammable gas environment now exists. An evaluation has been performed to assess the performance of the ventilation system during a hypothetical GRE. The purpose of this evaluation was to determine the potential for hydrogen concentrations exceeding the allowable limits at spark sources within the $\mathbf{W}-030$ ventilation system following a hypothetical GRE in tank 241-AY-101.

The potential for spark sources exists within the individual tank recirculation systems and primary ventilation system for the tank farm containing tank 241-AY-101. The recirculation ventilation system for tank 241-AY-101 will be de-energized to eliminate any spark sources in this potentially flammable gas tank. However, potential spark sources will still exist in the other $A Y$ and $A Z$ tanks and the primary ventilation system. Analyses were performed with the GOTHlthermal hydraulic computer code to evaluate the potential for hydrogen concentrations exceeding $25 \%$ of the Lower Flammability Limit (LFL) given a hypothetical GRE in tank 241-AY-101. The hydrogen concentration in the region of the remaining potential spark sources was the primary concern. The analyses considered three GREs, which are described in Section 4.1. Both the ventilation system pressure and flow response to the GRES, and the flammable gas transport and mixing were evaluated. The analyses demonstrated that a GRE in tank 241-AY-101 would not result in back flow into the other $A Y$ and $A Z$ tanks and the hydrogen concentration at the primary ventilation system exhaust fan would not exceed $25 \%$ of the LFL.

\footnotetext{
GOTH is a trademark of JMI, which is derived from GOTHIC - a registered
trademark of the EPRI Corp.
} 


\subsection{METHODOLOGY}

The methodology and modeling approach consisted of the following. First, data for tank 241-AY-101, and the tank farm Project W-030 ventilation system consisting of primary and recirculation ventilation systems geometric data was collected. This included system drawings, prior design calculations, and vendor data. Second, this data was used to prepare the input for the GOTH thermal hydraulic computer program (Thurgood 1992) using the HUB electronic engineering software, and the GOTH preprocessor. Finally, analyses of hypothetical GREs in tank 24l-AY-10l were simulated with the GOTH model. The results were graphed with the GOTH post processor and evaluated.

Figure 2-1 shows a schematic of the GOTH model used for the evaluation. The dome space of each tank is modeled as a single lumped parameter volume. The model and subsequent analyses did not evaluate the multi-dimensional effects of gas mixing in the dome space of tank 241-AY-101. The ventilation system is modeled with a series of one-dimensional connected volumes in a network model. A11 known flow resistances, significant valves, and components are modeled. The recirculation faris are modeled with appropriate fan curves. The inlet pressure at the primary exhaust fan is set at its design inlet pressure for normal operation. 
WHC-SD-WM-ER-592, Rev. 0

Figure 2-1. GOTH Computer Mode1.

famplt

Thu Jul 11 13:35:41 1996

GOTH Version 3.4 - April 1991

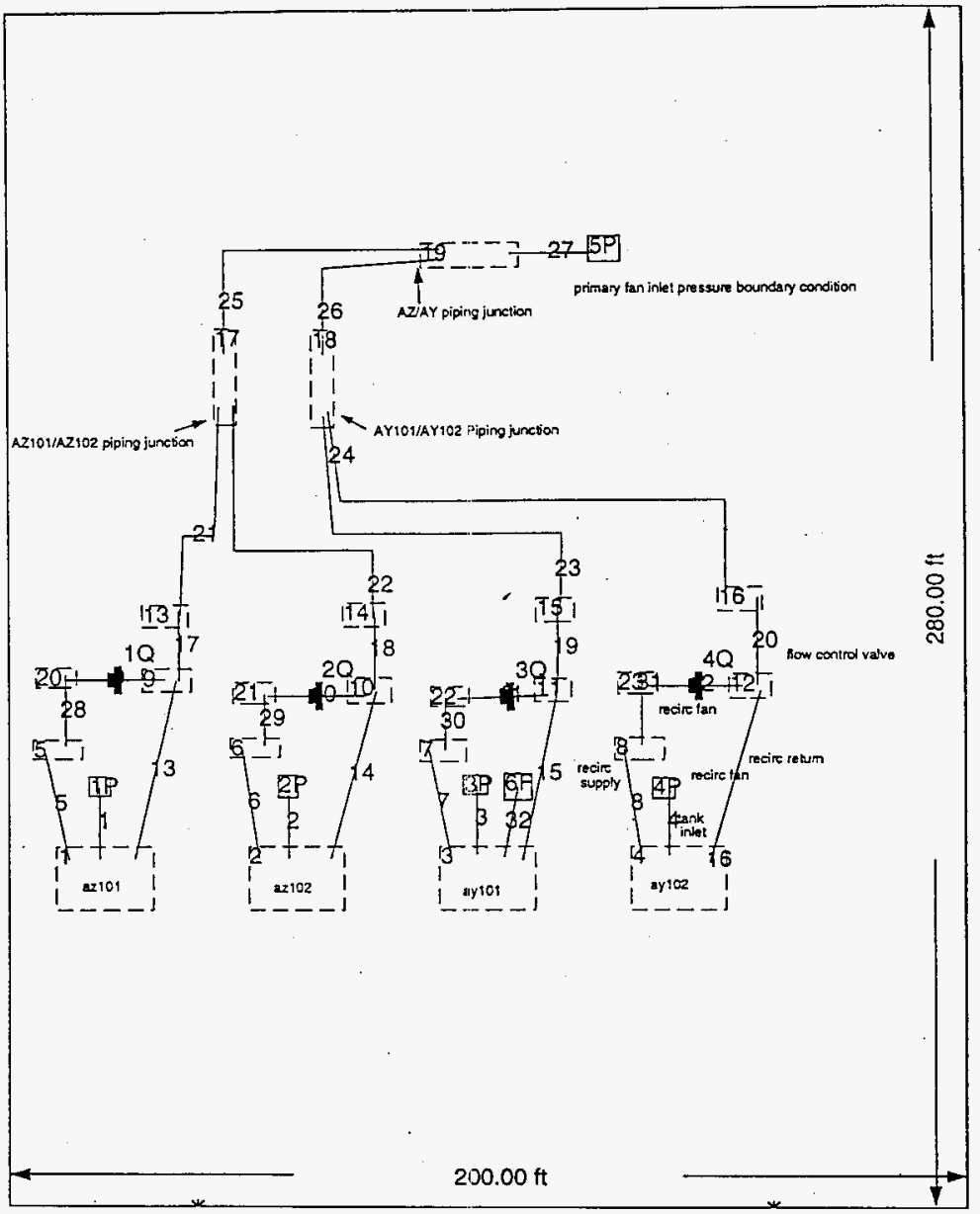


WHC-SD-WM-ER-592, Rev. 0

\subsection{ASSUMPTIONS, INPUT AND BASES FOR THE ANALYSIS}

\subsection{SYSTEM DESCRIPTION}

The 241-AZ/AY tank farm and associated Project $W-030$ ventilation system are illustrated below in Figure 3-1 in consistent geometric scale (WHC 1994). The system is shown schematically in Figures $3-2 a$ and $3-2 b$. An additional system description is contained in the noted reference (Friedrich 1994).

The normal system configuration is shown in Figure 3-2a. The tanks dome space pressure is maintained between 1-3 inches of $\mathrm{H}_{2} \mathrm{O}$ vacuum with a pressure controlled inlet valve. In normal operation, bleed flow from each tank's recirculation loop is limited to $100 \mathrm{cfm}$ using a flow control valve. The flow is monitored with a pitot tube flow meter located within the piping downstream of the junction between the recirculation loop piping and the primary system piping. The recirculation system was designed for a normal flow through the supply line to the recirculation condenser of $500 \mathrm{cfm}$, and the return flow of $400 \mathrm{cfm}$. The condenser, moisture separator, and recirculation fan are located upstream of the bleed flow junction. The primary system condenser, mist eliminator, heater, High-Efficiency Particulate Air (HEPA) filter, and exhaust fan are located in the primary vent building.

A second configuration which provides more dilution at the primary exhaust fan is shown in Figure 3-2b. The flow from tank 241-AZ-101 is increased from 100 to $500 \mathrm{cfm}$ by adjusting the primary exhaust fan inlet pressure and the system flow control valves. The flow from the remaining tanks is $100 \mathrm{cfm}$. This proposed system configuration is used for the Maximum Bounding GRE discussed in Section 4.1.3.

\subsection{ICF KAISER ENGINEERS DESIGN AND OPERATING BASIS}

In the design of the system for the design flow rates, the pressure drops for the recirculation and primary ventilation system were calculated by ICF Kaiser Engineers to provide a basis for specifying the head/flow requirements of the recirculation and primary fans (Umphrey 1992), (Rice 1992).

The index numbers for the piping system junctions/sections used in the design of the system are shown in Figure 3-3. These are referred to in following tables. The pressure drops in the system based on the original design flow rates are 1 isted Table $3-1$.

\subsection{WHC MODIFICATIONS OF THE OPERATING CONDITIONS BASED ON VENDOR SUPPLIED RECIRCULATION FAN}

The recirculation fan procured will provide more head at the design flow, and therefore more recirculation flow than the design basis (Vendor File l). In the model, the procured fan head/flow curve is used. To set the bleed flow control valves in the model at the approximate closure required to obtain $100 \mathrm{cfm}$ bleed flow, a steady-state balancing calculation was performed based on the prior ICF Kaiser results and the actual fan curve to obtain flow resistances, etc. as input to the GJTH model. The GOTH model was then run in 
the steady-state mode to insure that the model operated at the desired design conditions of 3 inches of $\mathrm{H}_{2} \mathrm{O}$ vacuum in each tank dome space, the primary exhaust fan inlet pressure at the design value, and with $100 \mathrm{cfm}$ at each tank's recirculation bleed flow to the primary system. The new revised operating conditions are summarized in Table 3-2.

The vendor supplied fan curve and a recirculation pressure drop versus flow curve based on the ICF Kaiser pressure drop calculations is provided in Figure 3-4. The recirculation supply flow based on the vendor-supplied fan curve and the hydraulic loss curve for the recirculation loop will result in recirculation supply flows of the order of $600 \mathrm{cfm}$.

\subsection{CONTROL SYSTEM OPERATION}

Under normal operation, the tank inlet control valve will adjust until the tank vacuum is at a set point of 1 to 3 inches of $\mathrm{H}_{2} \mathrm{O}$ vacuum. The bleed valve, which controls flow from the recirculation loop to the primary exhaust system, will adjust until the flow rate is $100 \mathrm{cfm}$. The primary exhaust fan speed will adjust until a pressure set point (yet to be defined) located between the HEME mist eliminator and the HEPA filters is reached. The set point will be defined during startup operations such that adequate vacuum is produced upstream of the fan to produce the desired vacuum in the tanks, plus allow closure of the bleed control valves adequate to provide valve flow control sensitivity. At $100 \mathrm{cfm}$, the valves must be closed to $10-50$ degrees of closure to have reasonable and significant flow control sensitivity.

Once the exhaust fan upstream pressure set point is established, the system should run with little control action unless filters begin to plug up. There will be minor control action to compensate for barometric pressure changes.

The recirculation bleed valve closure angle for each tank was computed based on the pressure drop required to limit flow to $100 \mathrm{cfm}$ (Nelson 1996), while still maintaining the overall system pressure balance and fan inlet pressure defined per ICF Kaiser's pressure drop calculations and modified by WHC as discussed above. These valva clasure angles provide valve flow sensitivity at each tank and are therefore reasonably close to that which will be selected during the startup operations.

\subsection{PIPING GEOMETRY}

The information required for the GOTH model on the piping geometry is summarized in Table 3-3. Piping lengths are calculated from west/north coordinates at the ends of each piping section (Drawing Set 1). Piping in the recirculation and primary systems consists of 8 and 10 -inch schedule 40 stainless steel pipe. 
Figure 3-1. Tank Farm 241-AY/AZ and W-030 Ventilation System Piping.

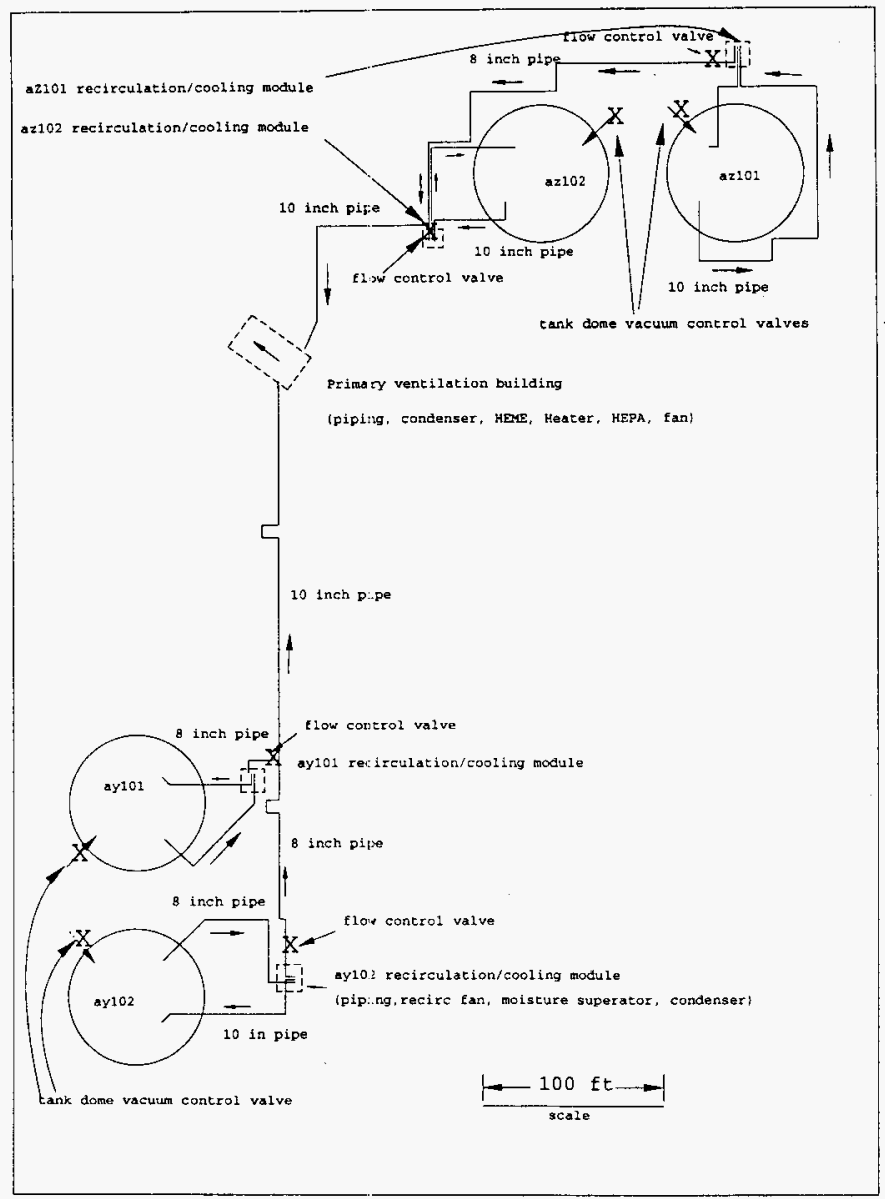


Figure 3-2a. Tanks 241 -AY/AZ W-030 Recirculation and Primary Ventilation System Schematic.

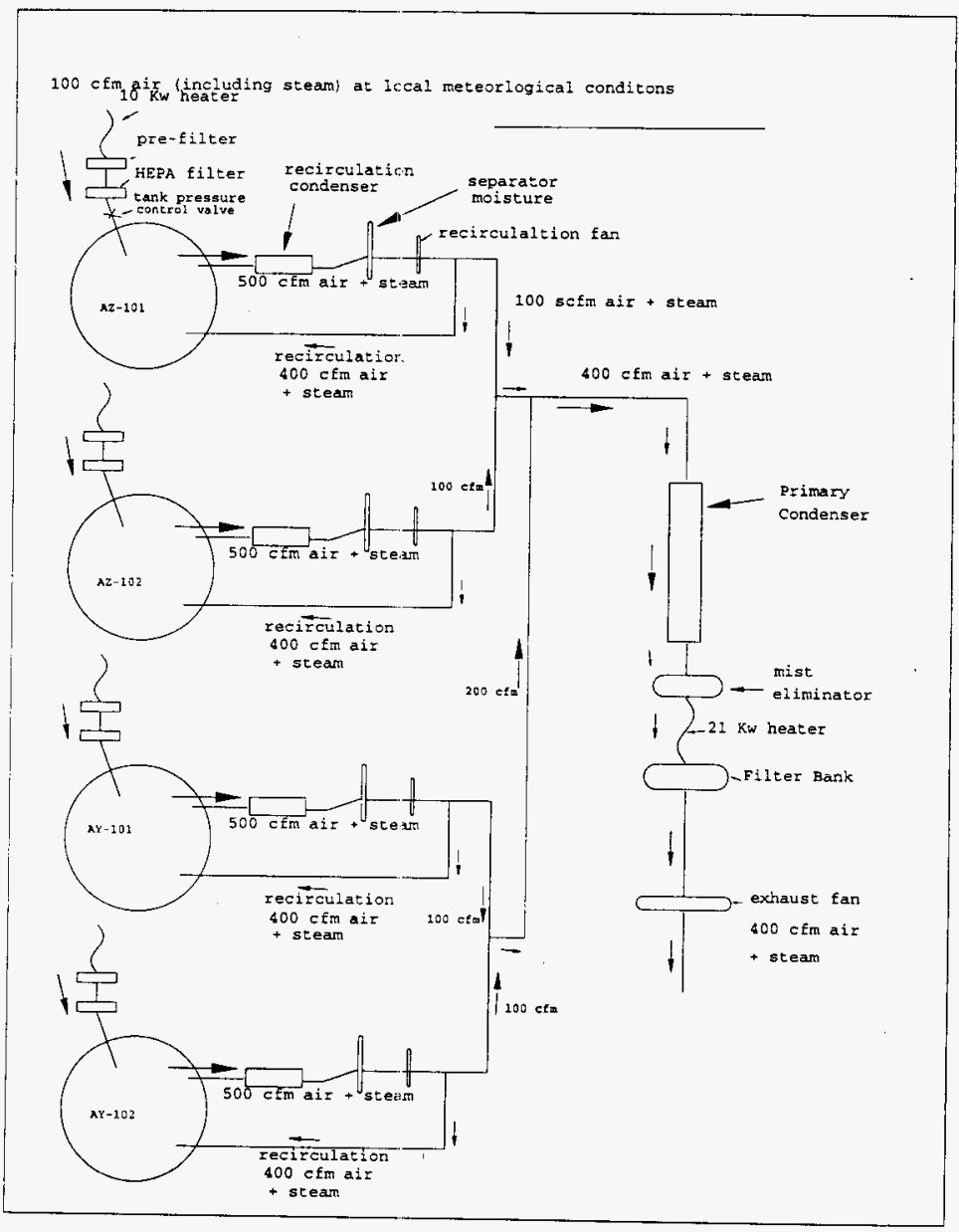


WHC-SD-WM-ER-592, Rev. 0

Figure 3-2b. Proposed W-030 Ventilation System Configuration.

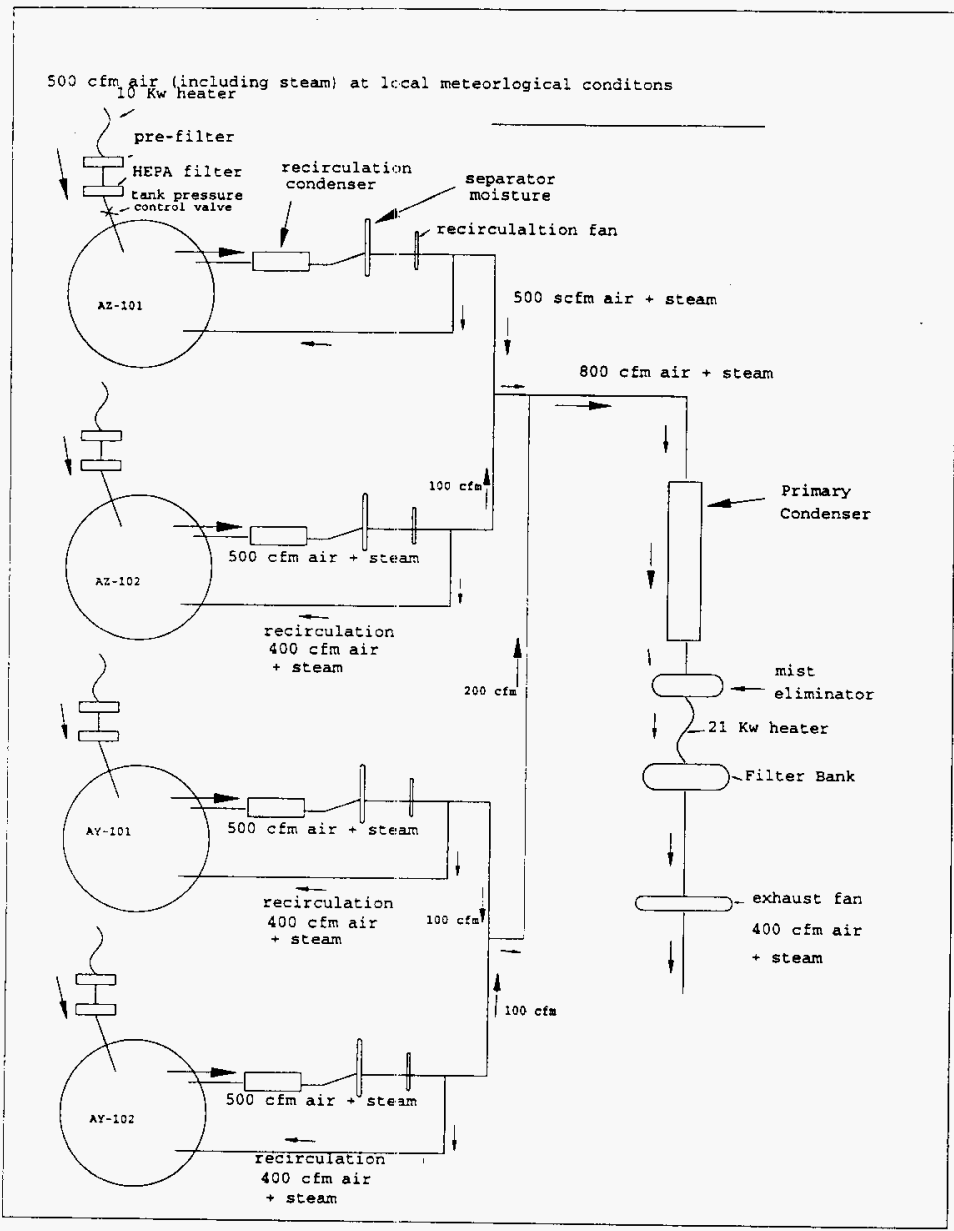


WHC-SD-WM-ER-592, Rev. 0

Figure 3-3. Tank Farm 241-AY/AZ and W-030 Ventilation System Piping Showing ICF Kaiser Section/Junction Numbering System.

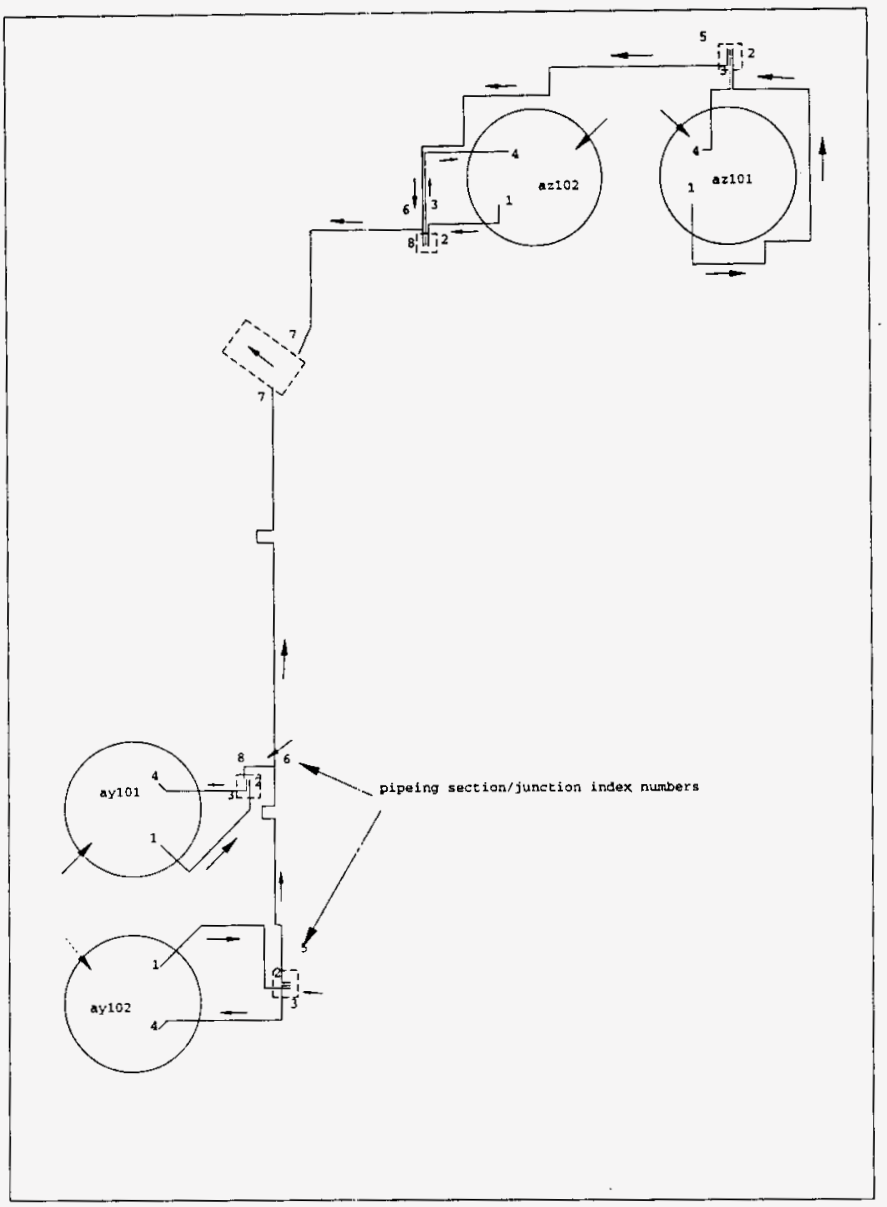


Table 3-1. ICF Kaiser Normal/Design Operating Pressure Drop and Pressures.

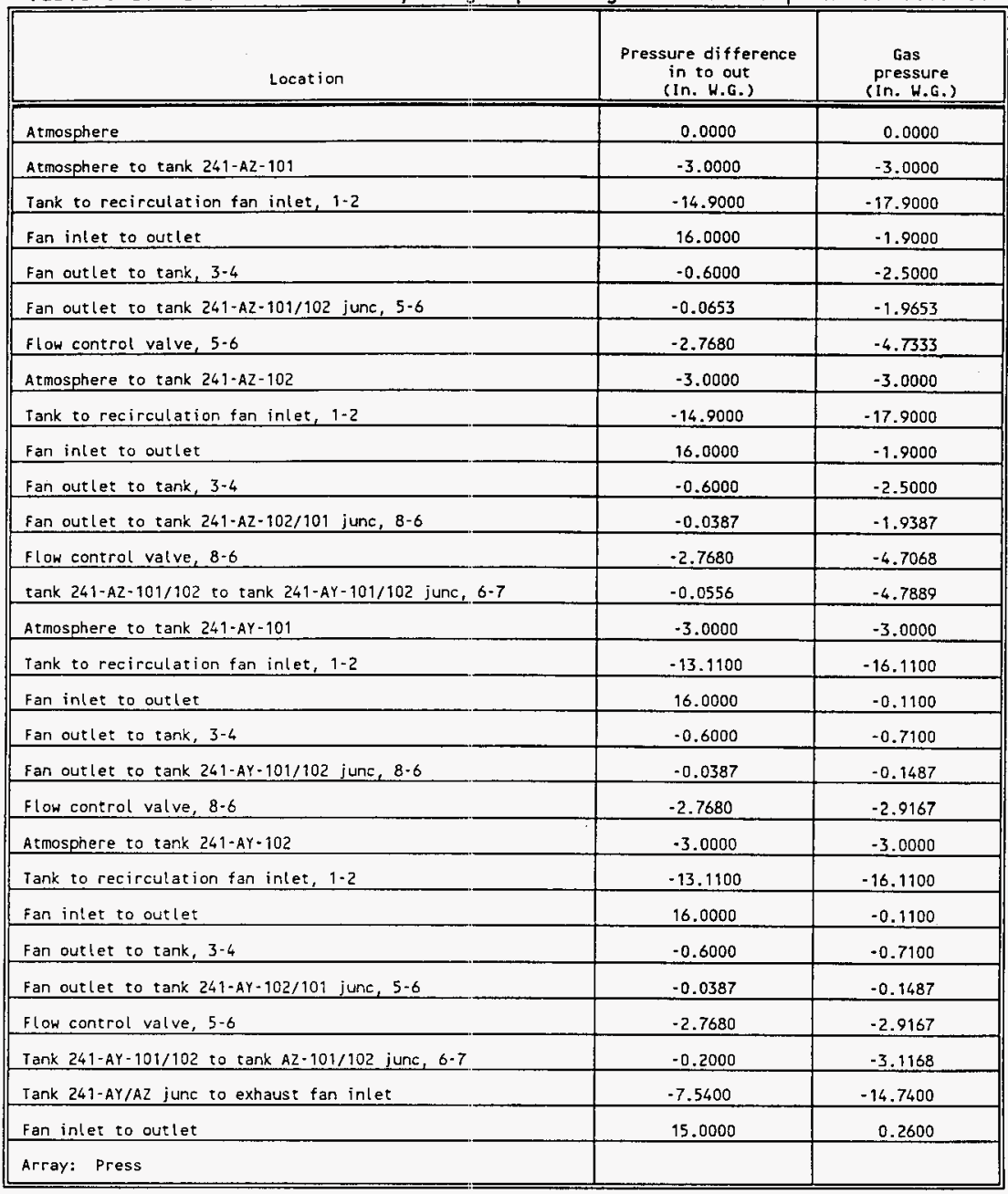


Table 3-2. WHC Modified Normal/Design Operating Pressure Drops and Pressure.

\begin{tabular}{|c|c|c|c|c|c|c|c|c|c|c|}
\hline Location & $\begin{array}{l}\text { Pressure } \\
\text { Difference } \\
\text { in to out }\end{array}$ & $\begin{array}{c}\text { gage } \\
\text { pressure }\end{array}$ & $\begin{array}{l}\text { gage } \\
\text { pressure }\end{array}$ & $\begin{array}{l}\text { Absolute } \\
\text { Pressure }\end{array}$ & $\begin{array}{c}\text { Absolute } \\
\text { Pressure }\end{array}$ & $\begin{array}{c}\text { Pipe } \\
\text { Diameter }\end{array}$ & $\begin{array}{c}\text { Volumetric } \\
\text { Flow } \\
\text { Rate }\end{array}$ & $\begin{array}{c}\text { cEquivalent } \\
\text { Klosg } \\
\text { based } \\
\text { on Pipe } \\
\text { Flow Axea }\end{array}$ & $\begin{array}{l}\text { Pipe Flow } \\
\text { Area }\end{array}$ & $\begin{array}{c}\text { Pipe } \\
\text { Gas } \\
\text { Velocity }\end{array}$ \\
\hline & inw & inW & psi & inW & psia & in & $\frac{f t^{3}}{\min }$ & & $f t^{2}$ & $\frac{\mathrm{ft}}{\mathrm{sec}}$ \\
\hline atmosphere & 0.000 & 0.000 & 0.000 & 406.91 & 14.70 & 0.00 & 0.00 & 0.00 & 0.00 & 0.00 \\
\hline Atm to Tank Az-10I & -3.000 & -3.000 & -0.108 & 403.97 & 14.59 & 6.07 & 100.00 & 194.26 & 0.20 & 8.31 \\
\hline Tank to Recirc Fan Inlet, 1-2 & $-19.91 \%$ & -22.918 & -0.828 & 383.99 & 13.87 & 10.02 & 578.10 & 287.51 & 0.55 & 17.59 \\
\hline Fan Inlet to outlet & 20.77 & -2.143 & -0.07 & 404.77 & 14.62 & 0.00 & 0.00 & 0.00 & 0.00 & 0.00 \\
\hline Fan outlet to Tank, 3-4 & -0.857 & -3.000 & -0.108 & 403.91 & 14.50 & 7.98 & 478.10 & 7.28 & 0.35 & 22.94 \\
\hline Fan outlet to A2101/102 junc, 5-6 & -0.065 & -2.200 & -0.08 & 404.70 & 14.62 & 7.98 & 100.00 & 12.65 & 0.35 & 4.80 \\
\hline Flow control value, $5-6$ & -4.936 & -7.144 & $-0.25 \%$ & 399.76 & 14.44 & $7.9 \mathrm{~g}$ & 100.00 & 958.41 & 0.35 & 4.80 \\
\hline Atm to Tank Az-102 & -3.000 & -3.000 & $-0.10 \%$ & 403.91 & 14.59 & 6.07 & 100.00 & 194.26 & 0.20 & 8. 31 \\
\hline Tank to Recirc Fan Inlet, 1-2 & -19.919 & -22.91 . & $-0.82 \mathrm{H}$ & 383.99 & 13.87 & 10.02 & 578.10 & 287.51 & 0.55 & 17.59 \\
\hline Fan Inlet to ourlat & 20.77 & $-2.14=$ & -0.07 & 104.73 & 14.62 & 0.00 & 0.0ิ & 0.00 & 0.00 & 0.00 \\
\hline Fan outlet to Tank, 3-4 & -0.85 & -3.000 & $-0.10 \mathrm{f}$ & 403.91 & $14.5 \mathrm{~s}$ & 7.98 & 478.10 & $7.2 \mathrm{~g}$ & 0.35 & 22.94 \\
\hline Fan outlet to $A 2201 / 101$ june, B-6 & $-0.03 \phi$ & -2.182 & $-0.07 q$ & 404.73 & 14.62 & 7.98 & 100.00 & 7.52 & 0.35 & 4.80 \\
\hline Flow control valve, $8-6$ & -4.967 & $-7.14 d$ & -0.258 & 399.70 & 14.44 & 7.98 & 100.00 & $963.5 \mathrm{~s}$ & 0.35 & 4.80 \\
\hline AZ101/102 to AY $101 / 102$ junc, 6-7 & -0.050 & -7.200 & -0.260 & 399.7 & 14.44 & 10.02 & 200.00 & 6.70 & 0.55 & 6.09 \\
\hline Atm to Tank Ay-101 & -3.000 & -3.000 & -0.108 & 403.97 & 14.55 & 6.07 & 100.00 & 194.26 & 0.20 & 8.31 \\
\hline Tank Inlet to Recirc Fan Inlet, 1-2 & $-19.45 \$$ & -22.45 & -0.811 & 384.45 & 13.85 & 10.02 & 609.20 & 252.97 & 0.55 & 18.58 \\
\hline Fan Inlet to outlet & 20.427 & -2.028 & -0.073 & 404.89 & 14.63 & 0.00 & 0.00 & 0.00 & $0.0 \mathrm{~d}$ & 0.00 \\
\hline Fan Outlet to Tank, 3-4 & -0.973 & -3.000 & -0.108 & 403.91 & 14.59 & $7.9 \mathrm{~g}$ & 509.10 & $7.2 \mathrm{~g}$ & 0.35 & 24.42 \\
\hline Fan outlet to AY101/102 junc, 8-6 & -0.039 & $-2.06 t$ & -0.075 & 404.84 & 14.63 & $7.9 \mathrm{~g}$ & 100.00 & 7.52 & 0.35 & 4.80 \\
\hline Flow control valve, 8-6 & -4.931 & -7.000 & -0.253 & 399.91 & 14.45 & $7.9 \mathrm{~d}$ & 100.00 & 957.83 & 0.35 & 4.80 \\
\hline Atm to Tank Ay-102 & -3.000 & -3.000 & -0.108 & 403.91 & 14.59 & 6.07 & 100.00 & 194.26 & 0.20 & 8.31 \\
\hline Tank to Recirc Fan Inlet, 1-2 & -19.45 & -22.45 & -0.811 & 384.45 & 13.89 & 10.03 & 609.10 & 252.97 & 0.55 & 18.58 \\
\hline Fan Inlet to outlet & 20.427 & -2.02 & -0.073 & 404.88 & 14.63 & 0.00 & 0.00 & $0.0 \mathrm{~d}$ & $0.0 \mathrm{~d}$ & 0.00 \\
\hline Fan outlet to Tank, 3-4 & $-0.97 t$ & -3.000 & $-0.10 \mathrm{~g}$ & 403.91 & 14.50 & 7.98 & 509.10 & 7.28 & 0.35 & 24.42 \\
\hline Fan outlet to AY102/101 junc, 5-6 & -0.039 & -2.06 & -0.075 & 404.84 & 14.63 & 7.98 & 100.00 & 7.52 & 0.35 & 4.80 \\
\hline Flow control valve, 5-6 & -4.933 & -7.000 & -0.25 & 399.91 & 14.45 & 7.98 & 100.00 & 957.83 & 0.35 & 4.80 \\
\hline AY $101 / 102$ to $A 2101 / 102$ junc, $6-7$ & -0.200 & -7.200 & -0.260 & 399.71 & 14.44 & 10.02 & 200.00 & 24.12 & 0.55 & 6.09 \\
\hline AY/Az junc to exhaust fan inlet & -7.540 & -14.740 & -0.532 & 392.12 & 14.17 & 10.02 & 400.00 & 227.3 & 0.55 & 12.17 \\
\hline Exhaust Fan Inlet to outlet & 15.000 & 0.260 & 0.009 & 407.27 & 14.71 & 0.00 & 0.00 & 0.00 & 0.00 & 0.00 \\
\hline \multicolumn{6}{|l|}{ Árray: $* * *$} & \multicolumn{5}{|c|}{ Array: $* * * *$} \\
\hline
\end{tabular}


WHC-SD-WM-ER-592, Rev. 0

Figure 3-4. Recirculation Fan Characteristics.

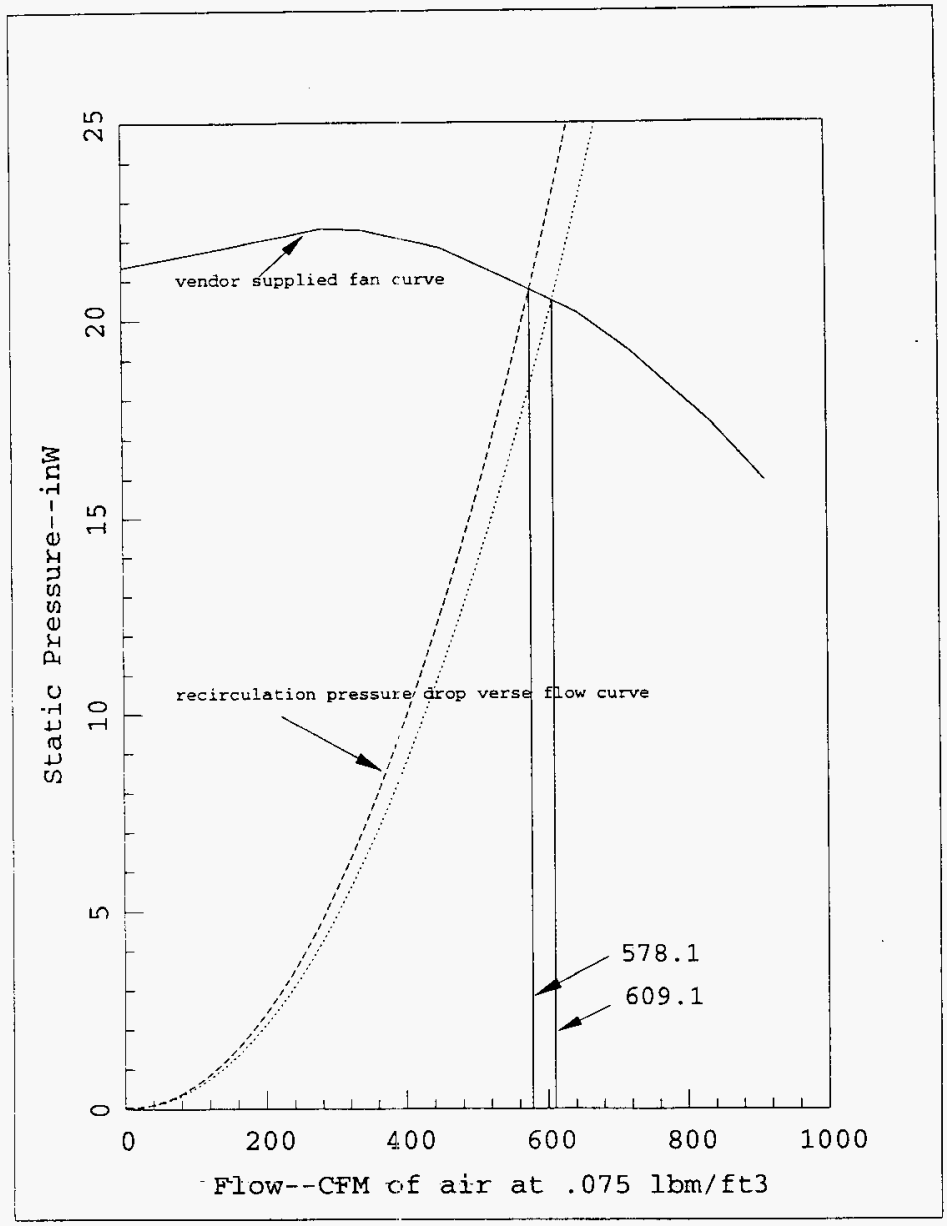




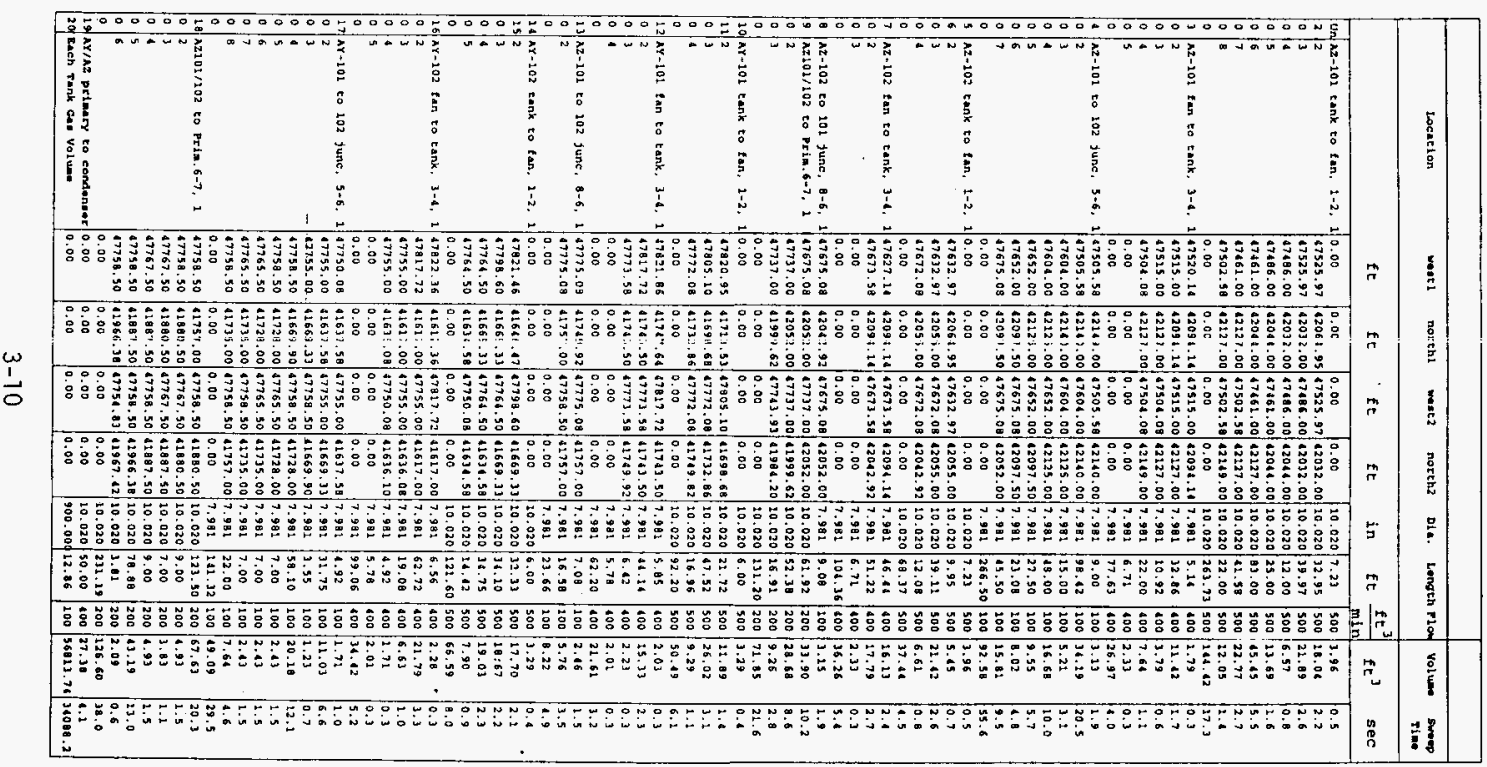




\subsection{DE-ENERGIZING TANK 241-AY-101 RECIRCULATION SYSTEM}

To eliminate spark sources in the tank 241-AY-101 recirculation system it has been proposed to de-energize that system. The details of whether the supply line would be valved out have not been developed. Whether the supply line is valved out or not, based or the above pressure drop table, in the deenergized mode, most of the $100 \mathrm{cfm}$ flow from the tank to the flow control valve will be in the return line, and the resulting pressure drop from the tank to the line will be very small. To compensate for the decrease in pressure upstream of the flow control valve, the valve can be set to a larger open angle to maintain the $100 \mathrm{cfm}$ through the valve and thereby maintain the same pressures and flows throughout the balance of the primary system.

Because it is not known at this time how the system will be de-energized for the simulations conducted, the recirculation system at tank 241-AY-101 was assumed to be energized. The results of the simulation would not change significantly if the simulation were conducted with the recirculation system de-energized, including the effects of resetting the control valve open angle. 
WHC-SD-WM-ER-592, Rev. 0

\subsection{ANAILYSIS ASSUMPTIONS}

\subsection{GAS RELEASE EVENT}

Three GREs were considered for the flammable gas evaluation of the Project $W-030$ ventilation system upgrade as described in the following section. In all cases, the limiting hydrogen concentration used for the evaluation was the Lower Flammability Limit (LFL) of $4 \%$ hydrogen.

\subsubsection{Maximum Pressurization GRE}

The spark sources for the Project $W-030$ ventilation system are the recirculation fans and equipment associated with each individual tank and the primary ventilation system exhaust fan. Although the equipment within AY-101 will be deactivated, back flow resulting from a large GRE may result in unacceptable hydrogen concentrations in tank 241-AY-102 or possibly the AZ tanks. To evaluate the potential for this back flow, an ultra-conservative, upper bound GRE was used (Maximum Pressurization GRE). The September 1992 GRE was one of the largest estimated GRE's for tank 241-SY-101. An estimate of the release was of the order of $15000 \mathrm{ft}^{3}$ (Wood 1993) with a release time of over 3 hours. While the total release volume was large, many releases in tank 241-SY-101 have occurred over shorter periods of time. Figure 4-1a shows a hypothetical release history used for the Safety Assessment for tank 241-SY101 mixer pump (Sullivan 1995). It consists of a rapid early release (10\%), followed by a steady release $(60 \%)$, followed by a decaying release $(30 \%)$. This is considered a bounding release history for tank 241-5Y-101. The September 1992 release volume was combined with the release history of Figure 4-la to provide a Maximum Pressurization GRE. This magnitude of the GRE is not possible for tank $A Y-101$ but used only as an very conservative upper bound to evaluate the potential for flow reversal resulting for a GRE. The release history and quantity associated with the larger value of $15000 \mathrm{ft}^{3}$ is shown in Figure 4-1b.

\subsubsection{Conservative GRE}

A conservative, but more realistic GRE was used to evaluate the potentia? for exceeding the hydrogen concentration limits at the primary exhaust fan. This conservative GRE (shown in Figure 4-1b) is based upon recent estimates of the maximum possible gas storage in 241-AY-101 (Hodgson 1996) of $3313 \mathrm{ft}^{3}$. The storage volume estimate was based upon a very conservative barometric pressure evaluation of all double-shell and single-shell tanks. The conservative GRE further assumes that the total inventory of gas is at tank bottom pressure. A release fraction of $50 \%$, which bounds a 11 know releases in tank 241-SY-101 was used. The total release into the dome space after expansion to atmospheric pressure from a tank bottom pressure of 30.6 psia is $3476 \mathrm{ft}^{3}$. The concentration of hydrogen within the released gas is assumed to be $50 \%$ by volume. This is an upper limit on the maximum possible $\mathrm{H}_{2}$ concentration. This upper limit is supported by recent Retained Gas Samples (RGS) from double shell tanks and physical arguments based upon the chemistry of the gas generation, which show that sludge gases are over $50 \%$ nitrogen and 
WHC-SD-WM-ER-592, Rev. 0

nitrogen compounds (Van Vleet 1996), leaving less than $50 \%$ as the maximum possible for hydrogen. The time history for the conservative release was based upon the 241-SY-101 mixer pump GRE discussed in the previous section. This conservative GRE, shown in Figure $4-1 b$, is a conservative and credible bounding GRE for the flammable gas evaluation of the Project $W-030$ ventilation system.

\subsubsection{Maximum Bounding GRE}

A third GRE was also used for the flammable gas evaluation. It adds another level of conservatism. This Maximum Bounding GRE derived from the Conservative GRE of the previous section. The assumed release fraction was increased from $50 \%$ to $100 \%$ of the trapped gas and the hydrogen concentration of the trapped gas was assumed to by $100 \%$. The release history of Figure 4.1 a was used. The total gas released to the dome space for the Maximum Bounding GRE is $6952 \mathrm{ft}^{3}$ as shown in Figure $4-1 \mathrm{~b}$. This is a very conservative GRE which bounds all credible releases in 241-AY-101. The flow was increased in tank 24l-AZ-101 to $500 \mathrm{cfm}$ for this release scenario to provide more dilution at the exhaust fan.

\subsection{CONTROL SYSTEM OPERATION DURING GRE}

During a GRE in tank 241-AY-101, the transient response would depend on the response characteristics of the control system and the controlled valves and fan. If the system response of the control valve is fast, then the following would be expected. The inlet valve will move toward closure as the pressure increases--finally closing if the pressure does not decrease as the valve begins to close. If the tank inlet valve moved to closure, no inflow into the tank would occur, nor would any outflow occur through the normal inlet paths--excluding uncontrolled leakage paths. The recirculation system outlet valve for tank 24l-AY-10l will also move toward closure, reducing flow to $100 \mathrm{cfm}$. If the valve control system were fast enough, then the flow from the recirculation system to the primary system of tank 241-AY-101 would not increase. In this case, the exhaust fan speed would not increase since pressures in the primary system would not increase.

If the valve control response was very slow compared to the time period of the GRE, then the inlet and recirculation system outlet valve would not close and the valves flow resistance would be essentially constant. In this case, flow into the tank through the normal inlet would decrease, and if pressure rises above atmospheric pressure during the GRE, the flow would reverse out the normal inlet path. Flow out of the recirculation bleed valve would increase, as would pressures in the primary system. This case would produce higher flows into the primary system, and higher pressures, potentially leading to back flow into other tanks' recirculation systems--when compared to the fast response control system scenario. Therefore, it is assumed for the simulations discussed in Section 5.0 that the control valve response is slow. 
WHC-SD-WM-ER-592, Rev. 0

Figure 4-1a. Normalized Hypothetical Release History.

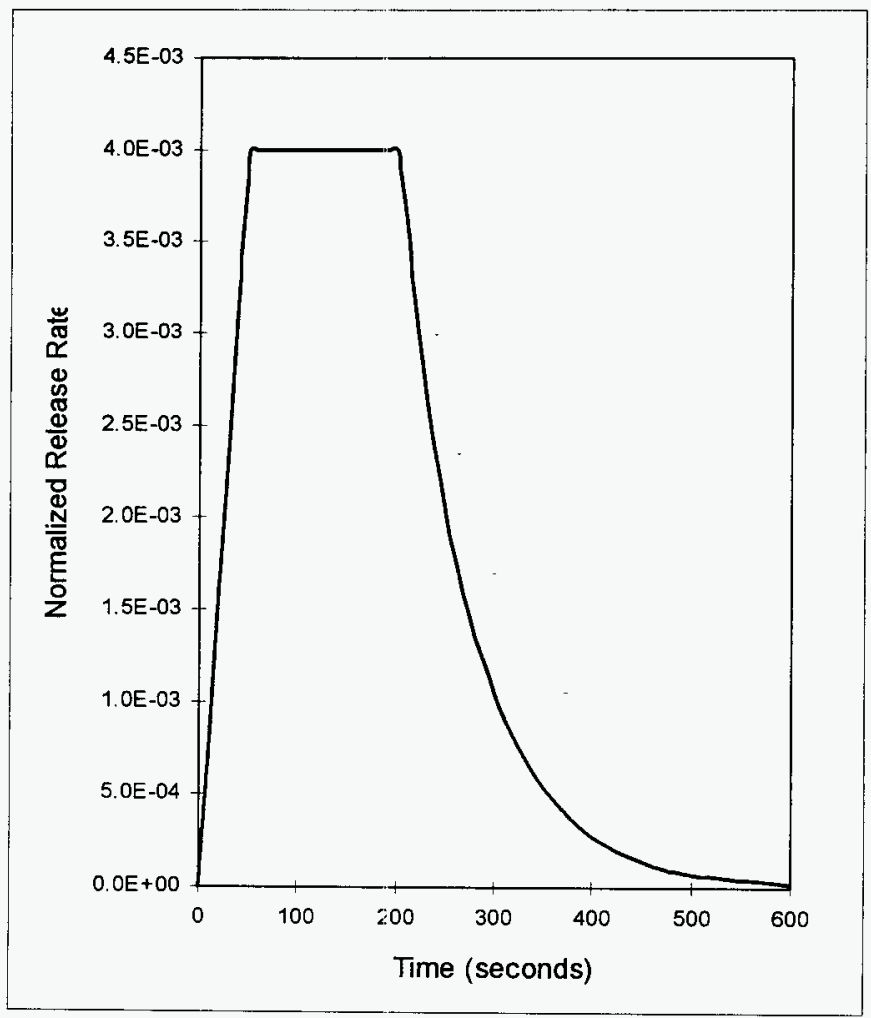


WHC-SD-WM-ER-592, Rev. 0

Figure 4-1b. Gas Release Events Assumed.

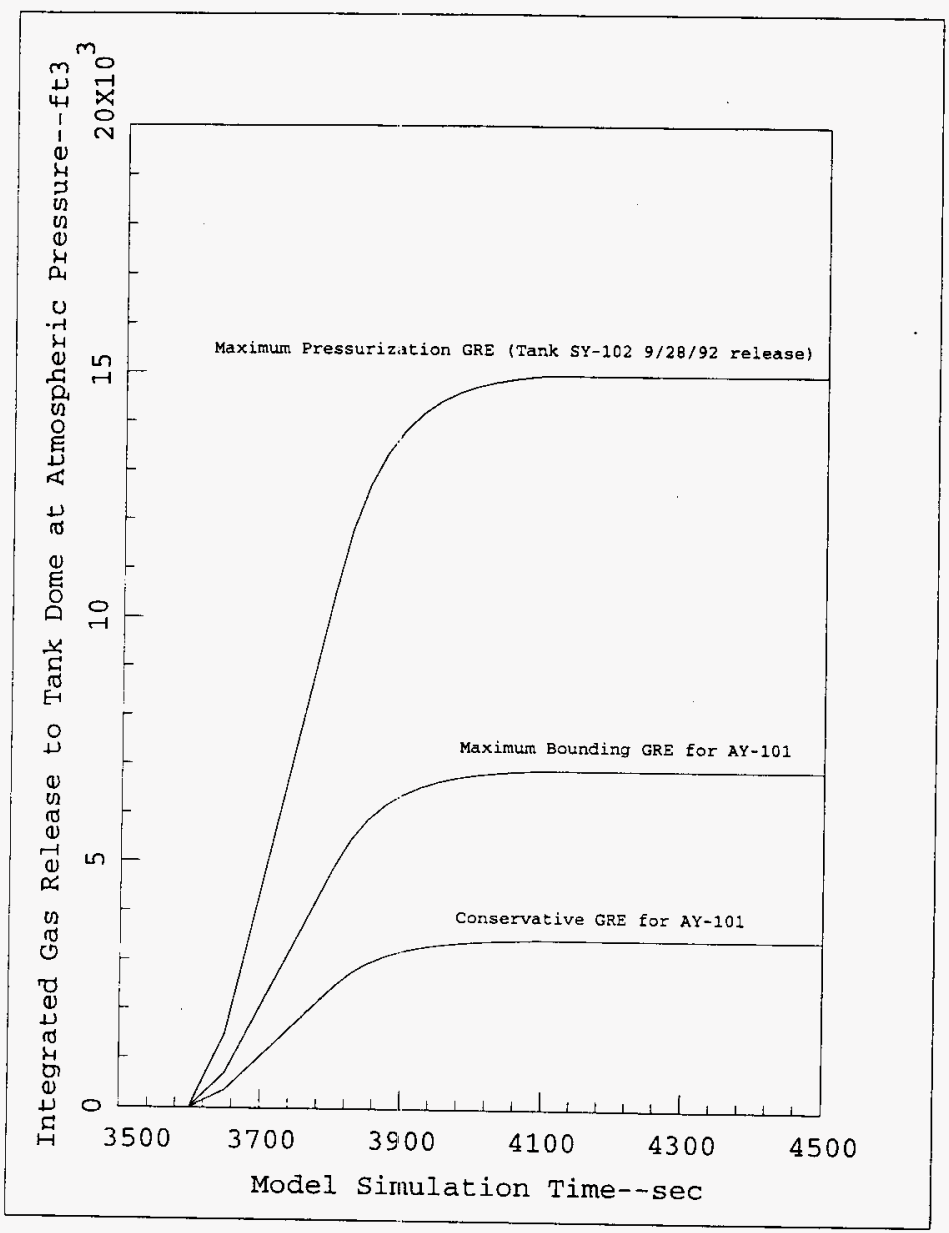




\subsection{RESULT:; OF THE EVALUATION}

An evaluation of the Project W...030 ventilation system was performed. The three GREs described in Section 4.1 were analyzed using the GOTH computer code. A description of the analyses is provided in the following sections.

\subsection{MAXIMUM PRESSURIZATION AND FLOW ANALYSES}

The results of the GOTH simulation model for the Maximum Pressurization GRE in tank 241-AY-101, its recirculation system, the primary system, and the other tanks are shown in Figures 5-1 through 5-5. As indicated in Figures 5-1 through 5-2, pressures within tank 241-AY-101 and its recirculation system change abruptly upon initiation of the release. The tank and recirculation system then return to near normal operation by end of the GRE. Tank pressure rises above atmospheric pressure anc reverse flow at the tank inlet occurs. Bleed flow from the recirculation lcop through the flow control valve to the primary system increases abruptly. As discussed previously, in this simulation the tank inlet pressure and recirculation bleed flow control valves are assumed to respond very slowly, maintaining a fixed open angle during the GRE. Flow in the recirculation system increases in the supply side and decreases in the return side due to the initial pressurization. Subsequently, as the system slowly depressurizes the loop flow is slightly below normal, and finally returns to normal.

Flow through the recirculation bleed flow control valves for each tank are compared in Figure 5-3. As shown, control valve flows decrease in tanks 241-AY-102, 241-AZ-101, and 241-AZ-102 rapid7y. A very small flow reversal occurs into tank 241-AY-102. However, the duration and flow rate are extremely small, and no hydrogen was carried to the recirculation systems of these tanks even under ultra-conservative gas release assumptions. Pressures downstream of the control valves are shown in Figure 5-4. Pressure increases are not large at these locations. Tank dome pressures are compared in Figure 5-5 and flows in the three main primary system branches are shown in Figure 5-6.

The results of the analyses of the Maximum Pressurization GRE demonstrate that an extremely conservative GRE in tank 24l-AY-101 results in a very short flow reversal into tank 24l-AY-102 but does not introduce flammable gas into the tank. Therefore, there is not a potential for flammable gas concentrations at the location of the recirculation fans that are of concern.

\subsection{CONSERVATIVE GRE-ANALYSES}

The ventilation system response for a significantly lower, but still conservative GRE was evaluated with the Conservative GRE shown in Figure 4-1b. The total release was $3456 \mathrm{ft}^{3}$. Graphical results similar to those discussed above for the Maximum Pressurization GRE are provided in Figures 5-7 through Figures 5-12. As would be expected, when compared to the larger release, the pressure and flow changes are significantly reduced. Pressure increases are 
large enough to cause reverse flow out the normal iniet of tank 241-AY-101. Flow at the tank 241-AY-101 outlet control valve doubles for a short period. The most significant change from normal operation is the flow out the tank 241-AY-10l recirculation bleed flow control valve as shown in Figure 5-9. Flows through the other tank outlet control valves decrease but do not reverse.

Hydrogen concentration in tank 24l-AY-10I dome space and the piping between the tank 241-AY/AZ piping junction exceeds $25 \%$ of the LFL (1\%) of hydrogen in air as shown in Figure 5-13. The flammability limit is not exceeded in this region. Downstream of the tank 241-AY-101/241-AY-102 piping junction towards the primary exhaust fan, the hydrogen concentrations just exceed $25 \%$ of the LFL for a very short period of time. Since there were no flow reversals towards the other tanks and the concentration of hydrogen in other tanks or recirculation systems will be at the normal tank operating concentration.

For the Conservative GRE, the hydrogen concentration exceeds $25 \%$ of the LFL in tank 24I-AY-10l dome space and piping system. The hydrogen concentrations at the primary exhaust fan, one of the locations of the potential spark sources locations, only briefly exceeds $25 \%$ of the LFL and does not exceed the LFL. Therefore, the hydrogen concentrations at the locations of the spark sources are within acceptable limits.

\subsection{MAXIMUM BOUNDING GRE ANALYSES}

The hydrogen concentration that would result due to release of $100 \%$ of the maximum estimated tank 241-AY-101 sludge gas (Maximum Bounding GRE shown in Figure 4-1b) at $100 \%$ hydrogen concentration was evaluated using the GOTH

model discussed in Section 2.0. A second ventilation system configuration was used for this analyses which was presented in Section 3.1. The bleed flow from tank 24l-AZ-10l was increased from $100 \mathrm{cfm}$ to $500 \mathrm{cfm}$ while maintaining $100 \mathrm{cfm}$ from the remaining tanks. This system configuration is intended to increase the dilution at the primary exhaust fan.

The time history of the hydrogen concentrations for the Maximum Bounding GRE analyses is shown in Figure 5-14. The hydrogen concentration in tank 241AY-101 dome space and the piping between the AY tanks and the AY/AZ piping junction, exceeds the LFL of $4 \%$ hydrogen. However, at the exhaust fan, a possible spark source, the hydrogen concentration exceeds $25 \%$ of the LFL but does not exceed the rimiting condition of $4 \%$ hydrogen (LFL).

Ventilation system flow rates through the flow control valves is shown in Figure 5-15. The rapid-GRE in tank 241-AY-101 reduces the flow from the other tanks. However, it results in only a small reverse flow similar to that seen in the Maximum Pressurization GRE (Section 5.1). Therefore, the recirculation fans do not present a hazard.

Thus, for this very conservative bounding case, the hydrogen concentration at the location of the spark source does not exceed acceptable limits. 
WHC-SD-WM-ER-592, Rev. 0

Figure 5-1. Pressure Within Tank 241-AY-101 and its Recirculation Systems.

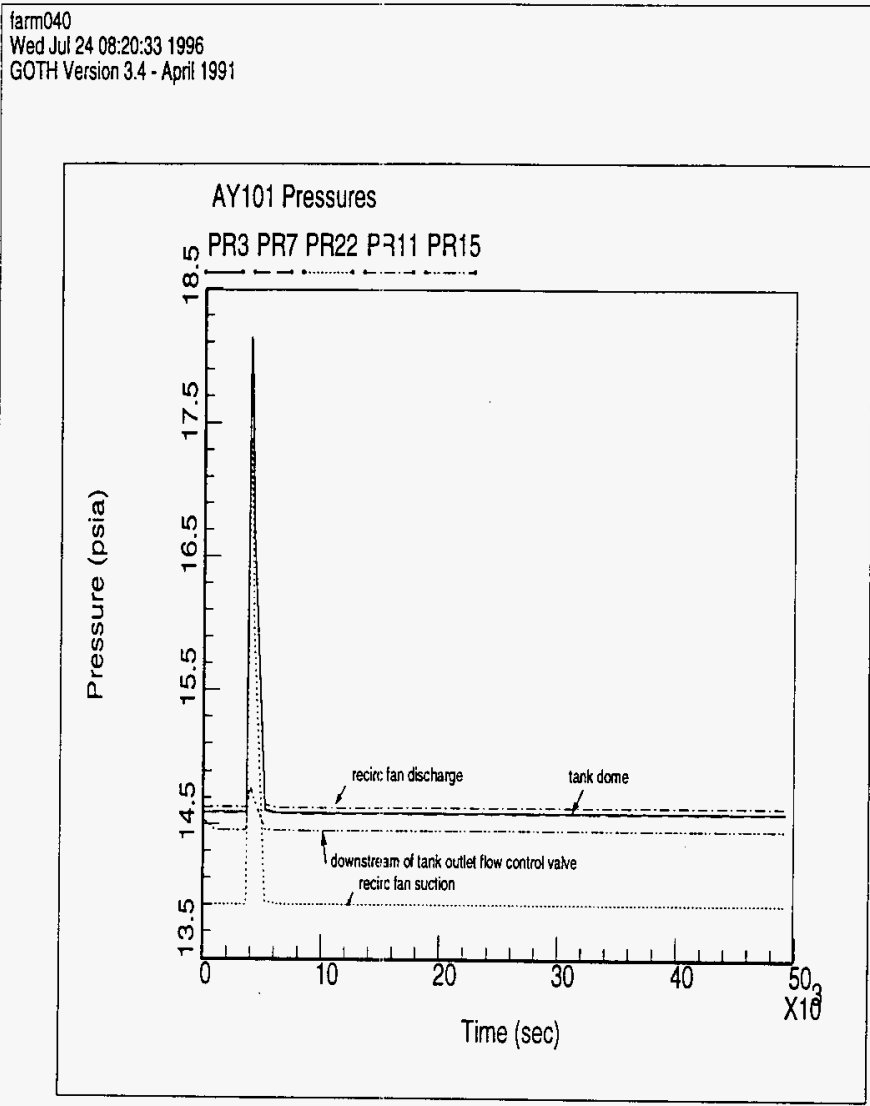


WHC-SD-WM..ER-592, Rev. 0

Figure 5-2. Flows Within Tank 241-AY-101 Recirculation System and Bleed Flow' to Primary System.

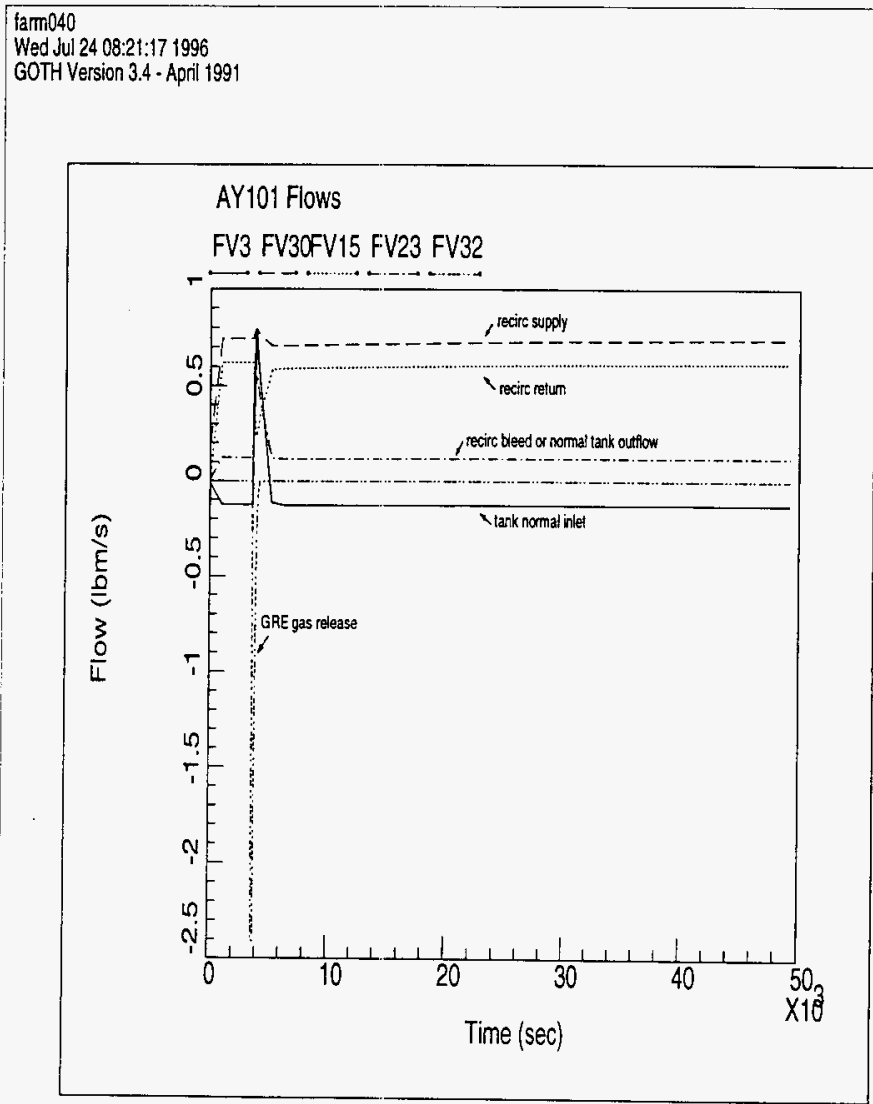


WHC-SD-WM-ER-592, Rev. 0

Figure 5-3. Flow Through Tanks Bleed Flow Control Valves.

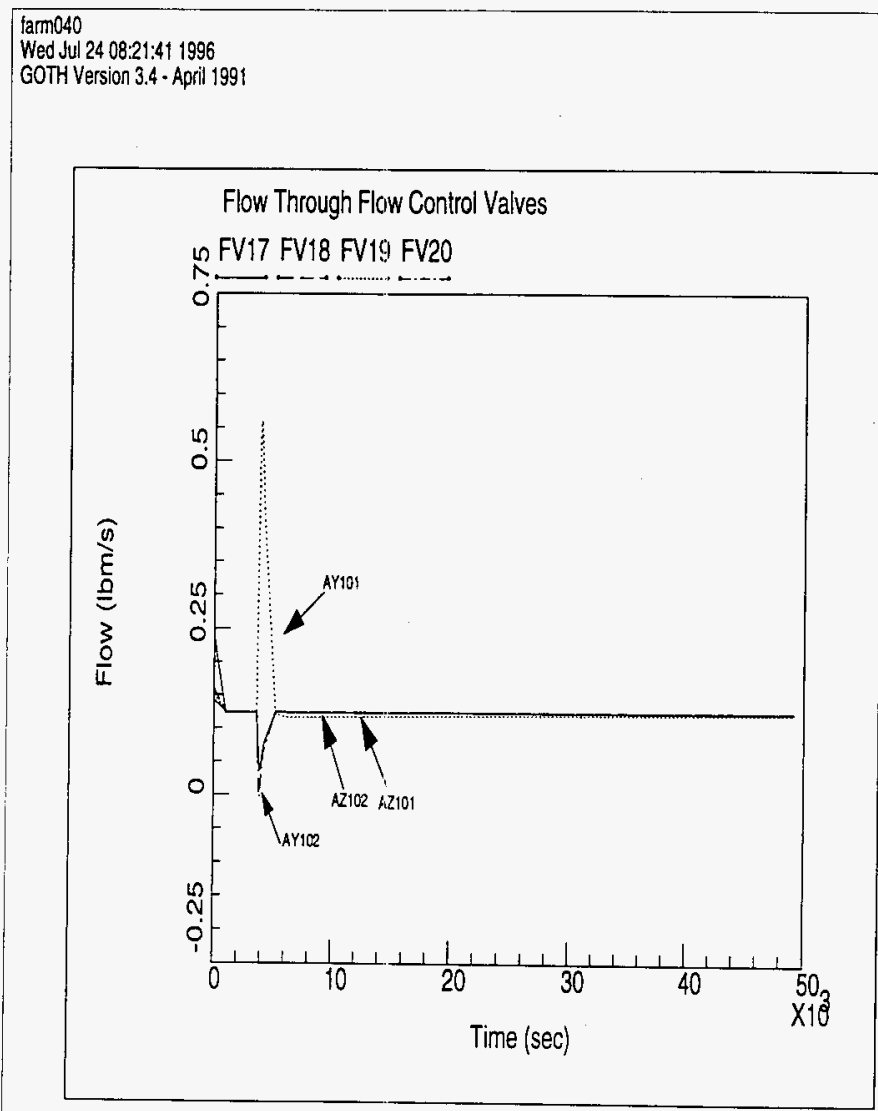


WHC-SD-WM-ER-592, Rev. 0

Figure 5-4. Pressures Dowristream of Flow Control Valves and Upstream of Primary Exhaust Fan Inlet.

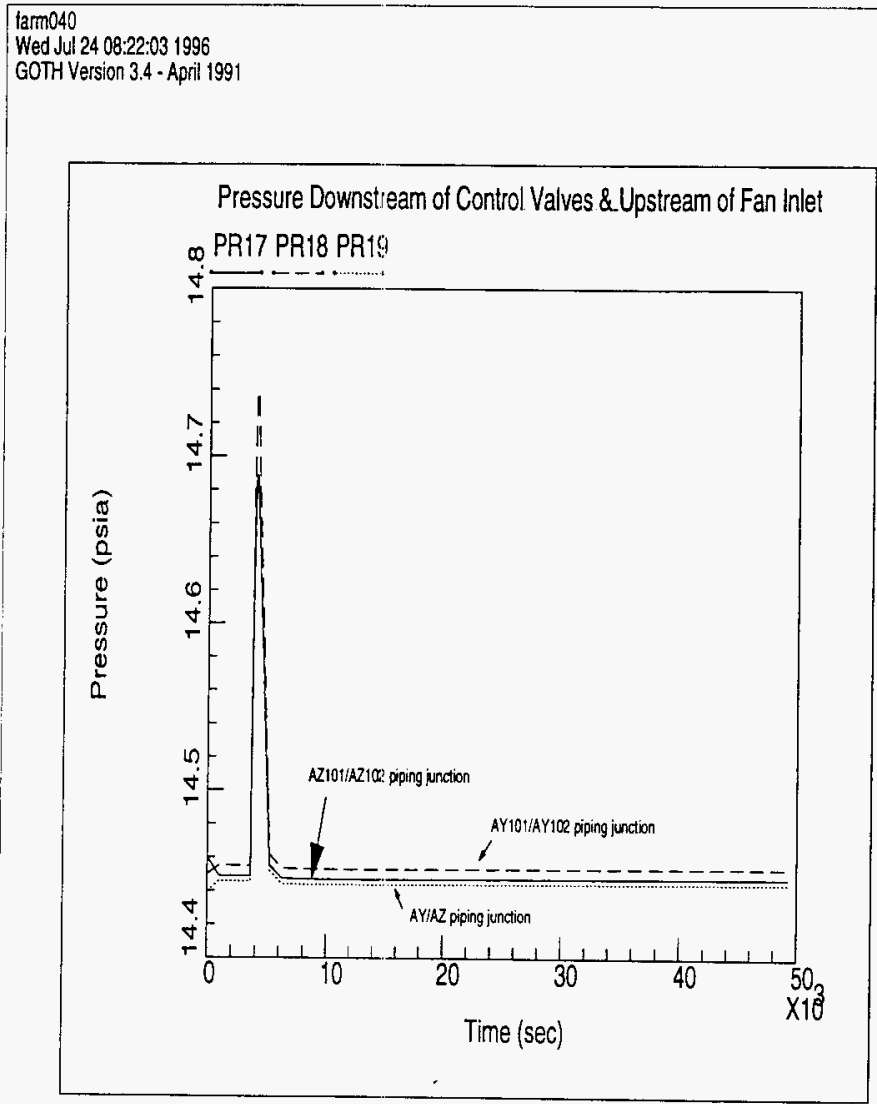


WHC-SD-WM-ER-592, Rev. 0

Figure 5-5. Tanks Dome Pressures.

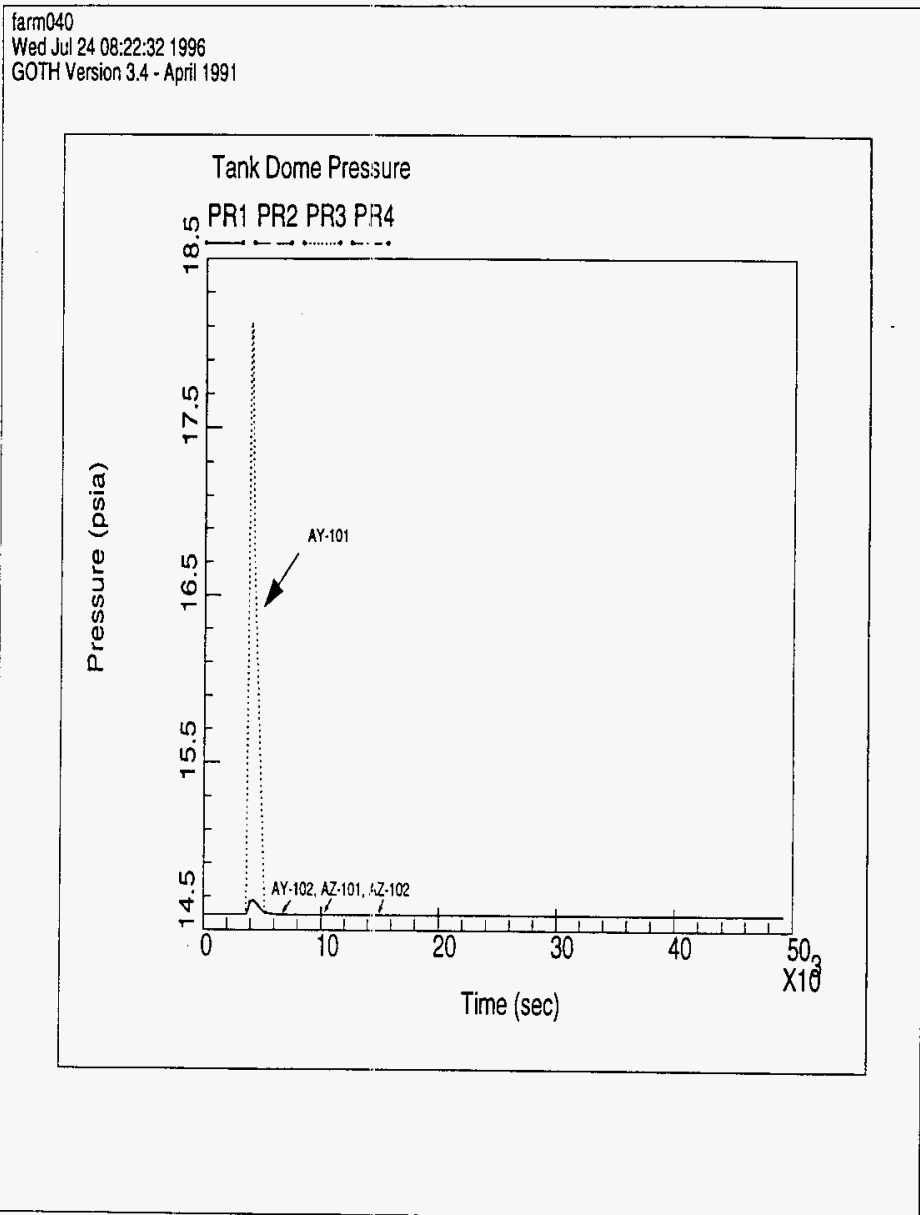


WHC-SD-WM-ER-592, Rev. 0

Figure 5-6. Flow in Primary System Manifold Piping.

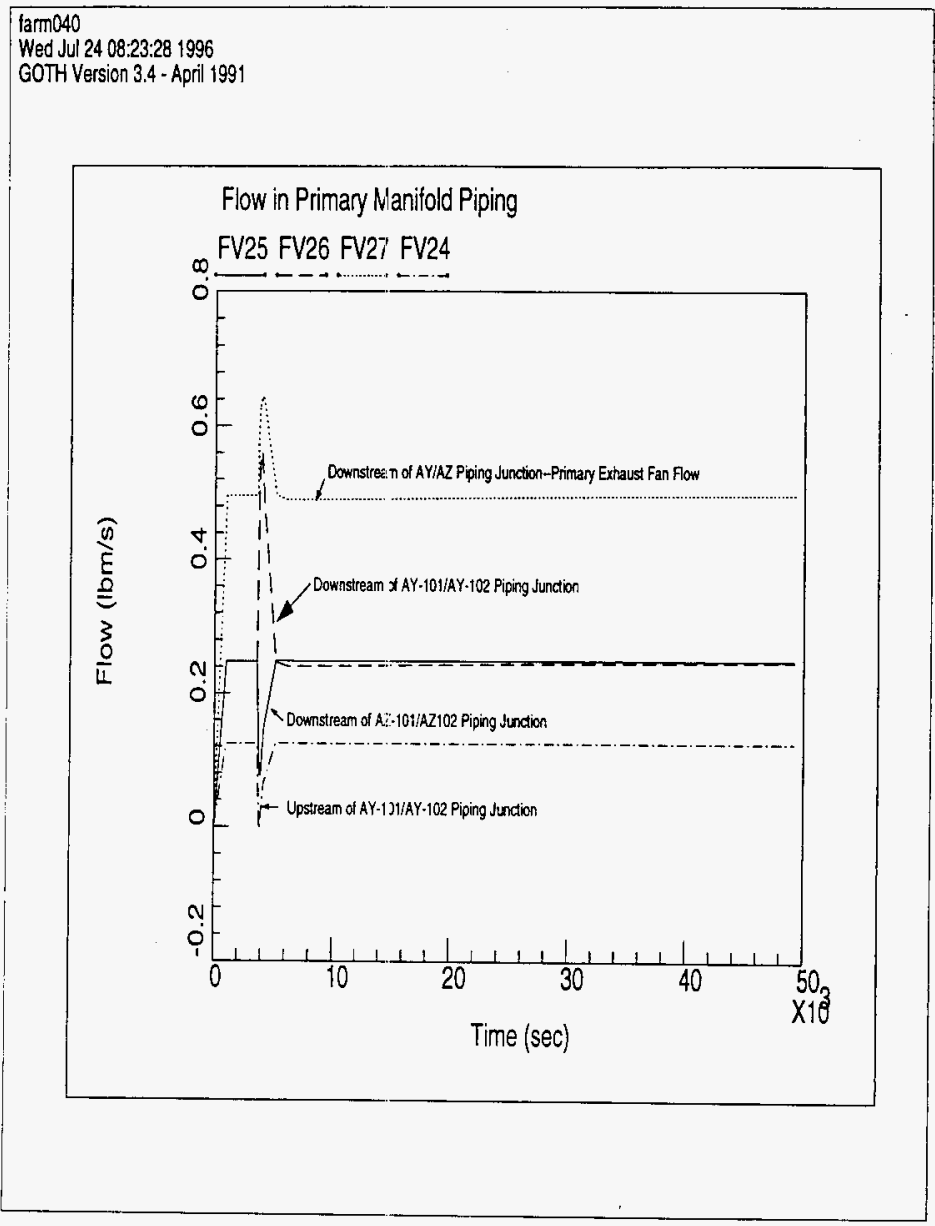


WHC-SD-WM-ER-592, Rev. 0

Figure 5-7. Pressures Within Tank 241-AY-101 and its Recirculation Systems.

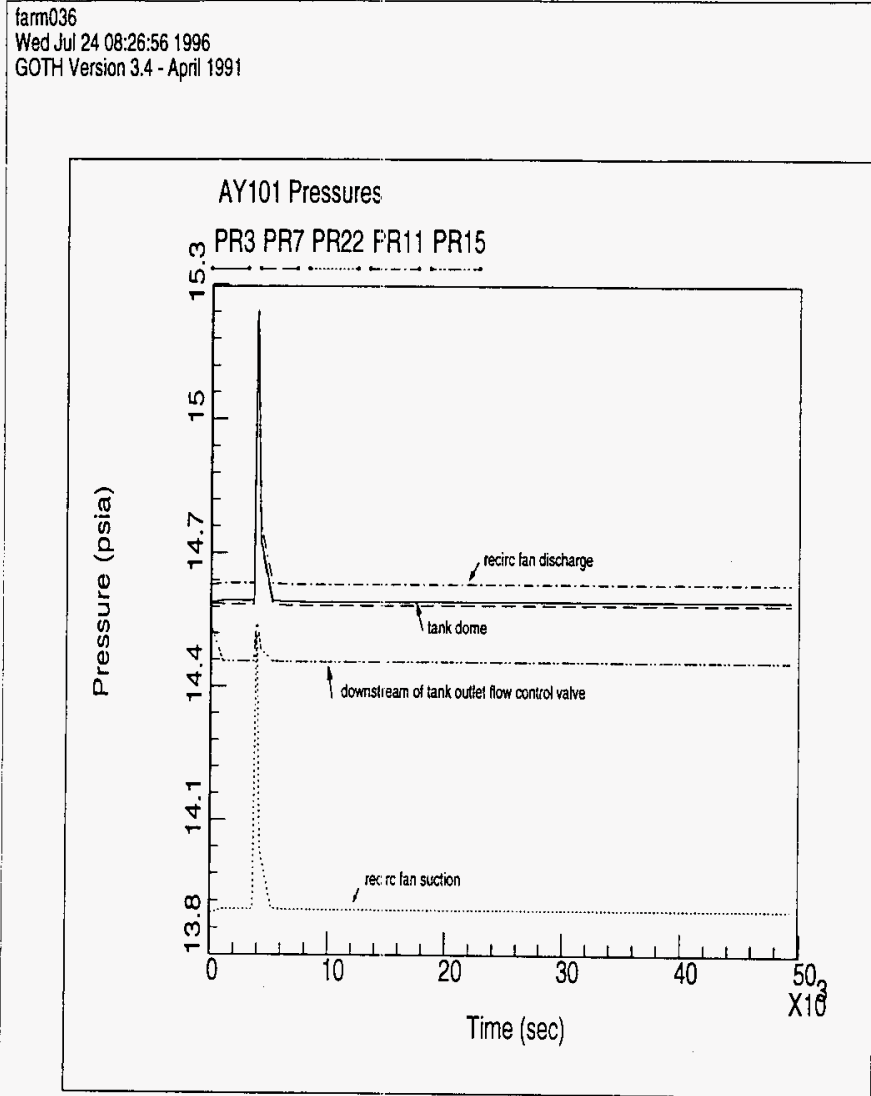


WHC-SD-WM-ER-592, Rev. 0

Figure 5-8. Flows Within Tank 241-AY-101 Recirculation System and Bleed Flow to Primary System.

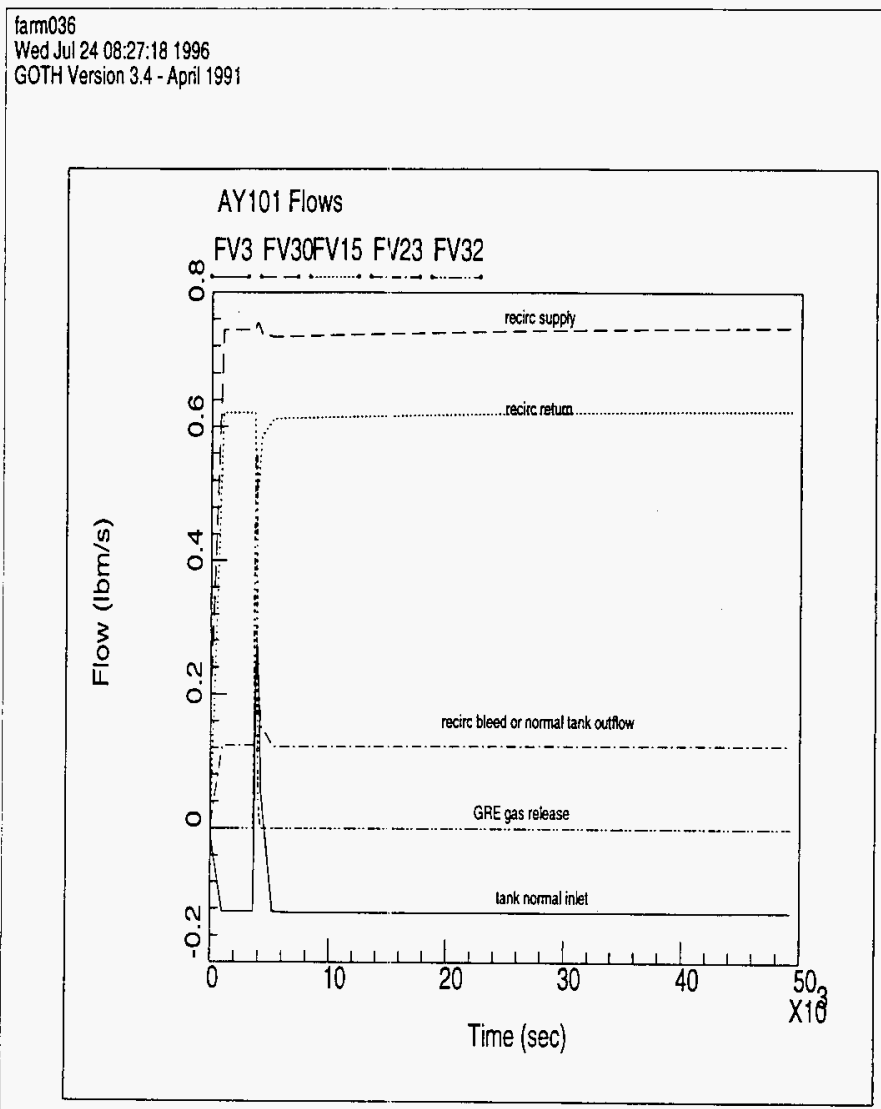


WHC-SD-WM-ER-592, Rev. 0

Figure 5-9. Flow Through Tanks Bleed Flow Control Valves.

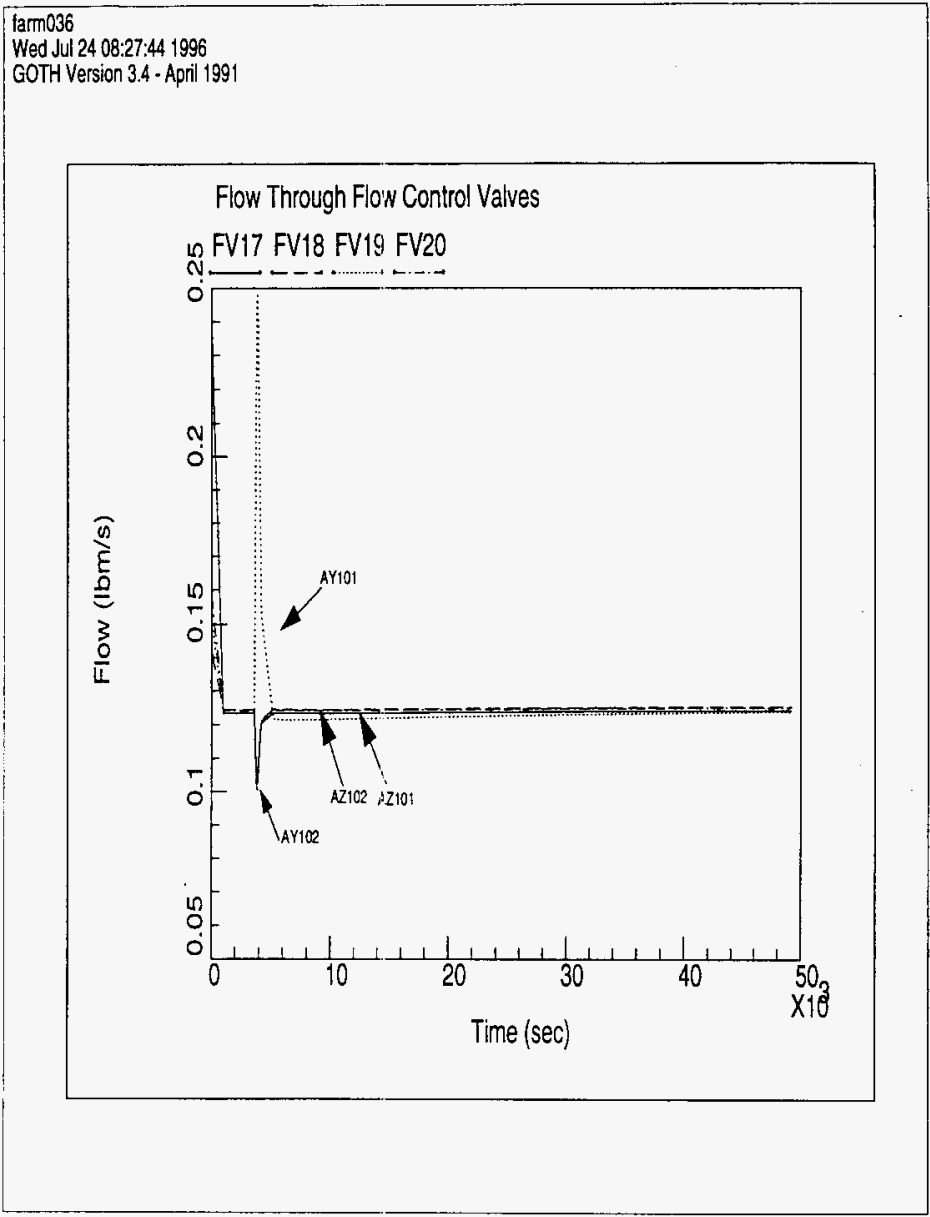


WHC-SD-WM-.ER-592, Rev. 0

Figure 5-10. Pressures Downstream of Flow Control Valves and Upstream of Primary Exhaust Fan Inlet.

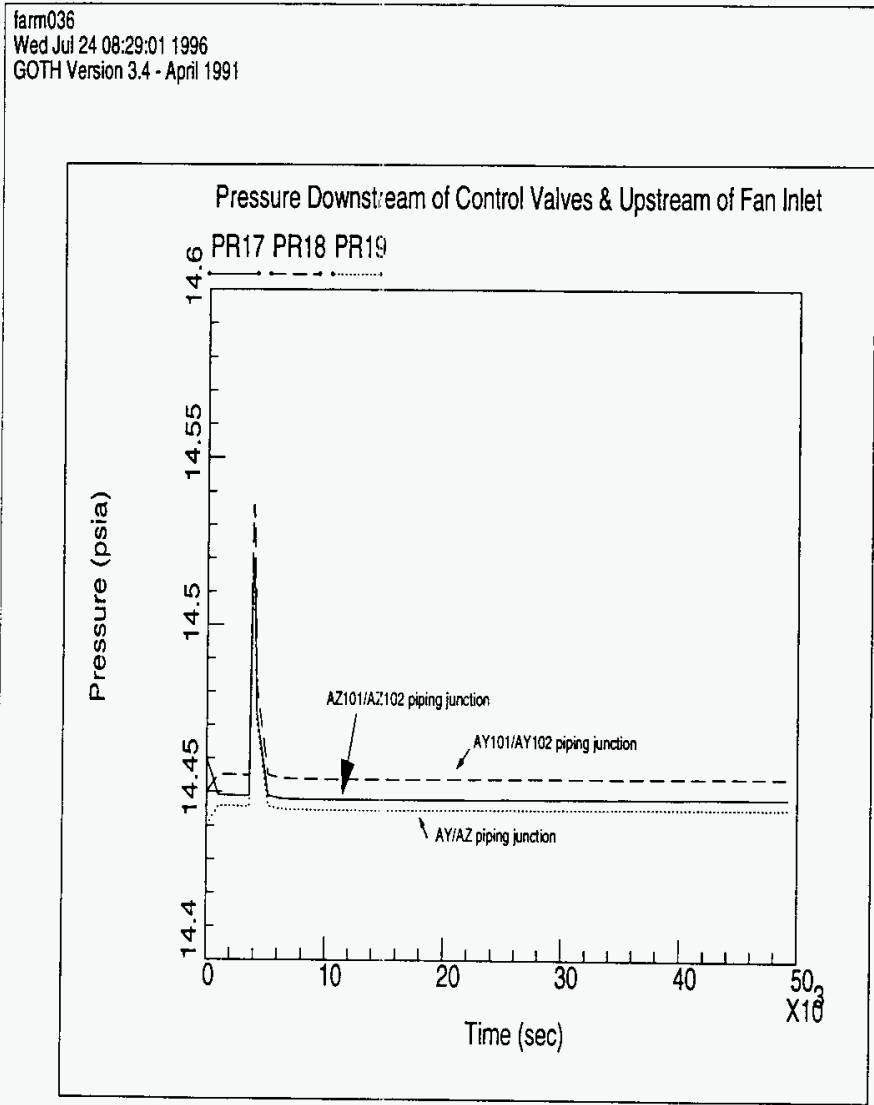


WHC-SD-WM-ER-592, Rev. 0

Figure 5-11. Tanks Dome Pressures.

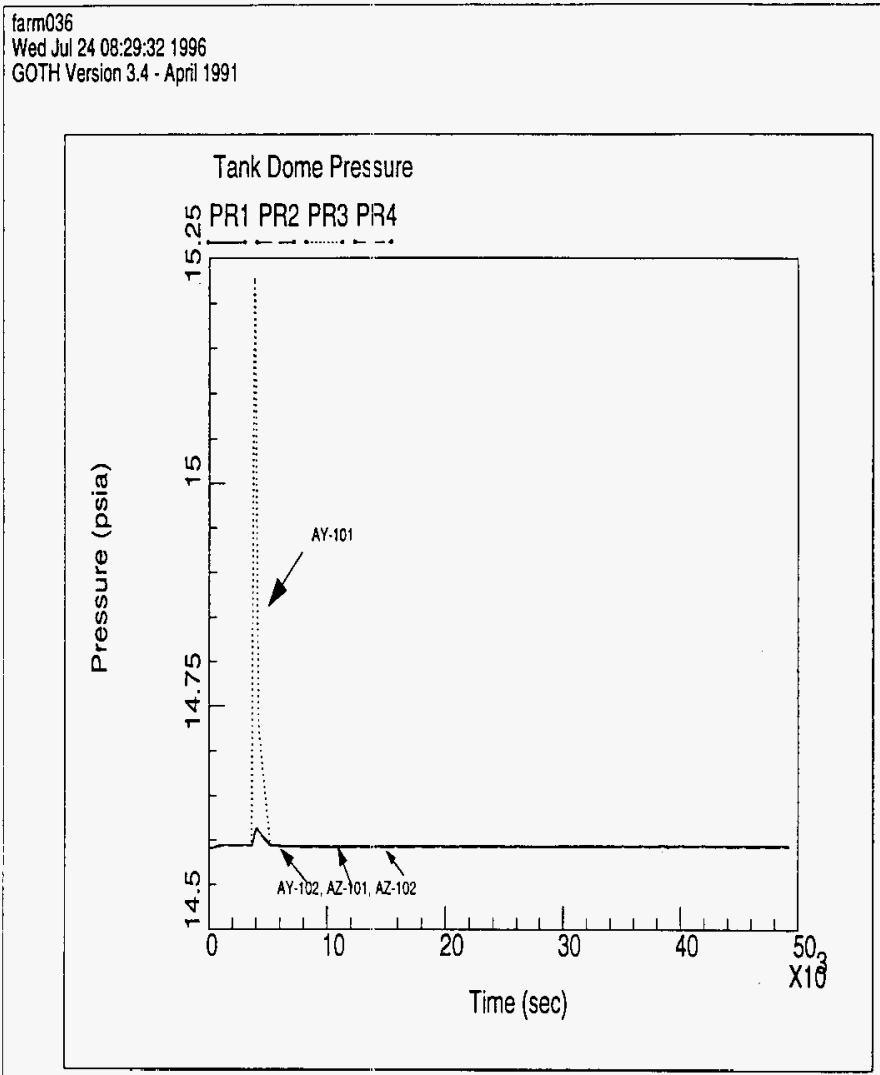


WHC-SD-WM-ER-592, Rev. 0

Figure 5-12. Flow in Primary System Manifold Piping.

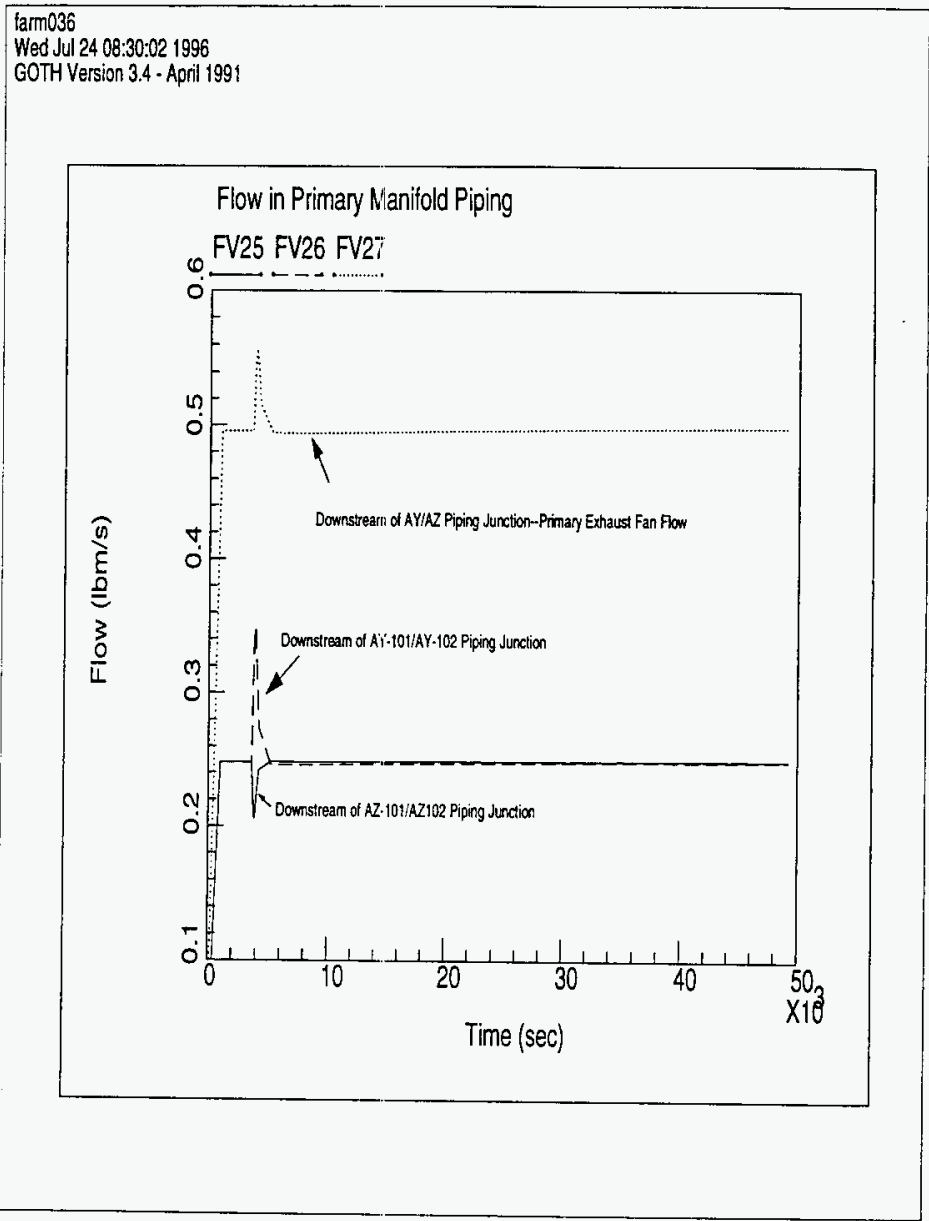


WHC-SD-WM-ER-592, Rev. 0

Figure 5-13. Hydrogen Concentrations for Conservative GRE.

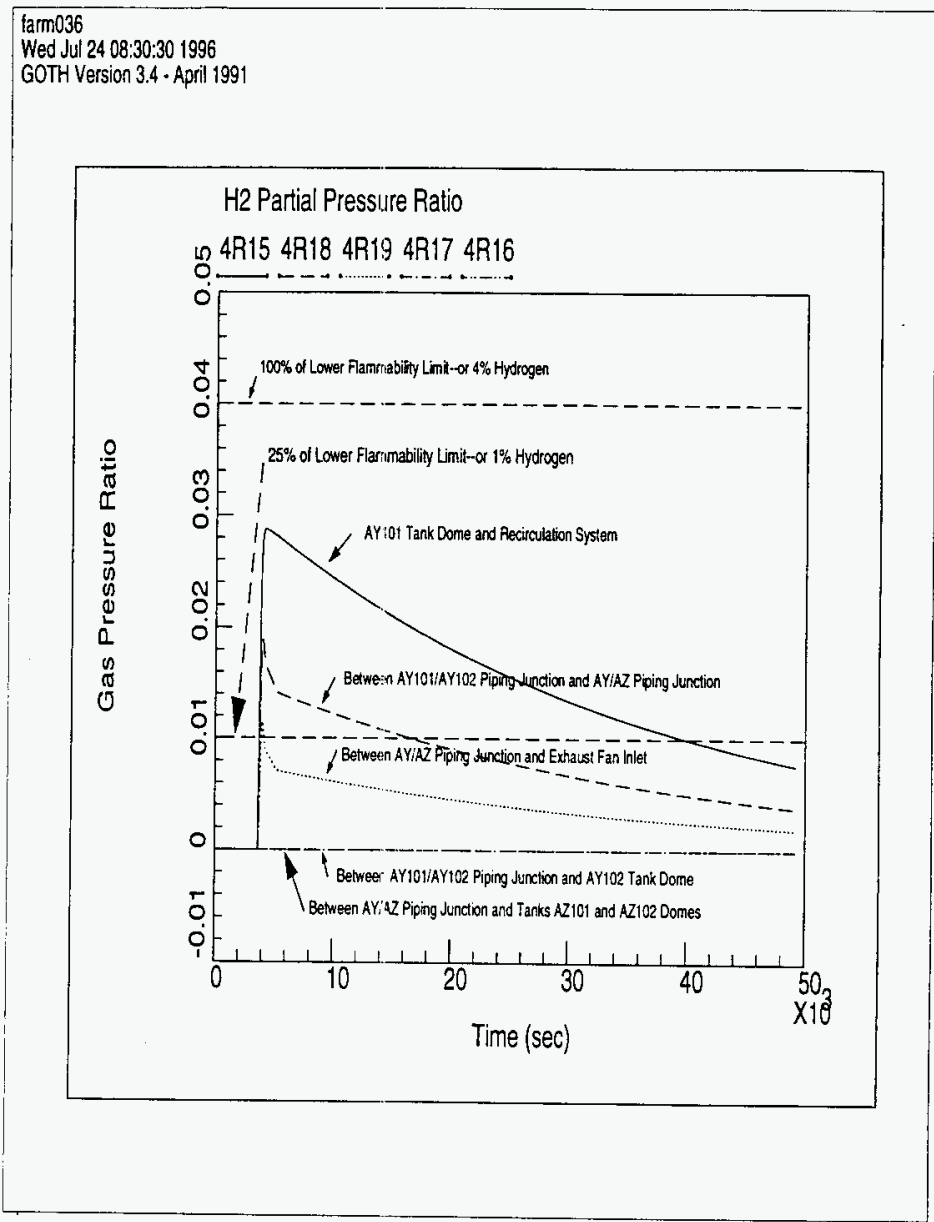


WHC-SD-WM-ER-592, Rev. 0

Figure 5-14. Hydrogen Conceritrations for Maximum Bounding GRE.

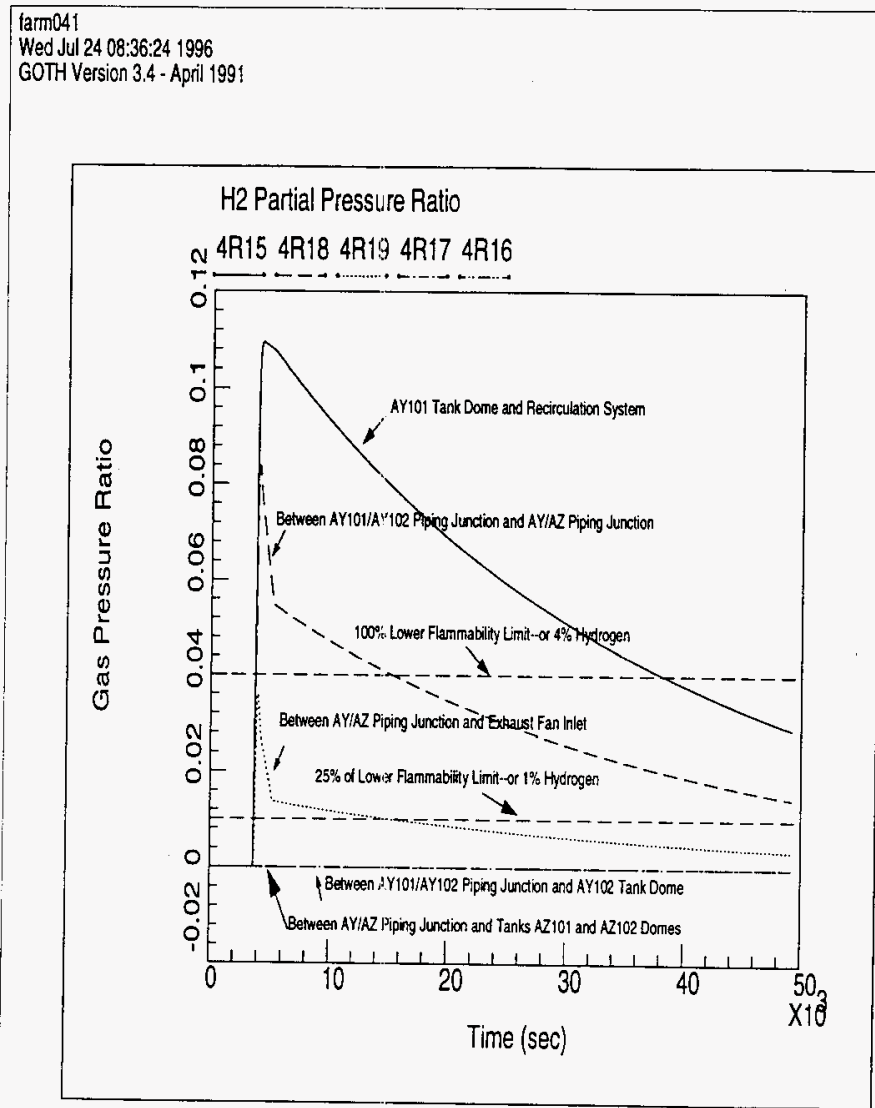


WHC-SD-WM-ER-592, Rev. 0

Figure 5-15. Flow Through Tanks Bleed Flow Control Valves for the Maximum Bounding GRE.

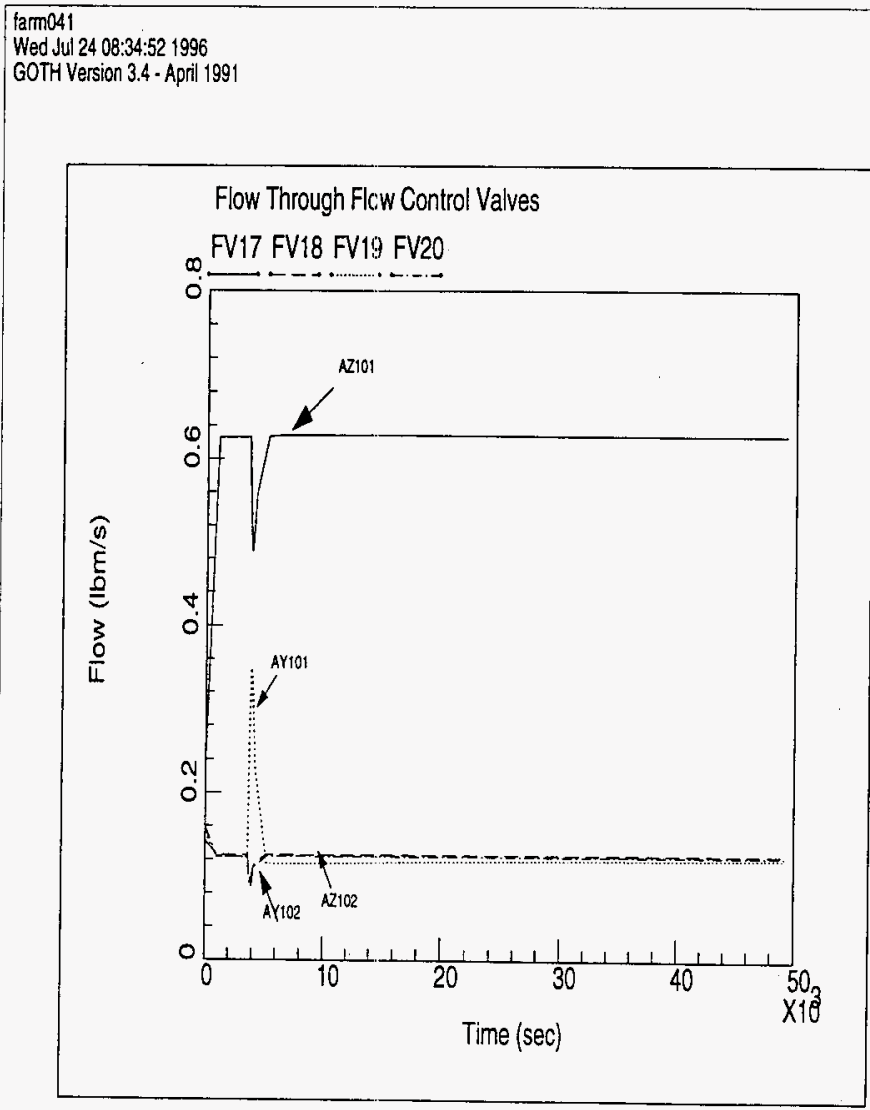


WHC-SD-WM-ER-592, Rev. 0

\subsection{CONCLUSIONS}

- The analyses of the Maximum Pressurization GRE demonstrated that a GRE in tank 241-AY-101 will result in only small back flow into the recirculation systems of other tanks in the AY/AZ farm. However, the duration is very short, with no transport of hydrogen to recirculation systems in the remaining tanks. Therefore, the spark potential of the recirculation fans are not a concern.

- The hydrogen concentration at the primary ventilation system exhaust fan exceeds $25 \%$ of the LFL but does exceed the LFL for the conservative and maximum bounding GREs in tank 241-AY-101.

- The maximum bounding GRE requires the additional dilution at the exhaust fan provided by the system configuration discussed in Section 3.1.

- The hydrogen concentration in the dome space of tank 241-AY-101 can exceed the LFL for the maximum bounding GRE. However, there are no available spark sources if the recirculation system of tank 241-AY-101 is de-energized.

- The evaluation of the Project W-030 ventilation system has shown that potential GREs in tank 241-AY-101 will not result in unsafe conditions resulting from the release of flammable gas. 


\subsection{REFERENCES}

Friedrich, M. A., and J. L. Henderson, 1994, Tank Farm Ventilation Upgrade System Descriptions, Project W-030, Engineering Data Transmittal 610205, ICF Kaiser Hanford Company, Richland, Washington.

Hodgson, K. M., 1996, Evaluation of Hanford Tanks for Trapped Gas, WHC-SD-WM-ER-526, Rev. 1, Westinghouse Hanford Company, Richiand, Washington.

Sullivan, L. Harold, 1995, Safety Assessment for Proposed Pump Operation Operation to Mitigate Episodic Gas Releases in Tank 241-SY-101, LA-UR-923196, Rev. 14, Los Alamos National Laboratory, Los Alamos, New Mexico.

Nelson, Mark, Valdisc Control Valves, Flow Coefficient Versus Degrees Open Table 2, Transmitted to Hanford, June 5, 1996, Control Elements, Inc., Portland, Oregon.

Rice, P., Calc. No. W030-023, Primary Ventilation Exhaust Fan Capacity, November 30, 1992, Kaiser Eng ineers Hanford, Richland, Washington.

Thurgood, M. J., et al., 1992, Simulation of Gas Release Event in Tank 101-SY Using the GOTH Computer Program, WHC-SD-WM-ER-150, Rev. 0, Prepared by Numerical Applications Inc. for Westinghouse Hanford Company, Richland, Washington..

Umphrey, M. r., Ca7c. No. W-030-014, W-030 HVAC Tank Farm Vent Piping Pressure Drop, October 20, 1992, Kaiser Engineers, Hanford, Richland, Washington.

Van Vleet, R. J., 1996, Safety Basis for Activities in Single-Shell Flammable Gas Watch List Tanks, Appendix, WHC-SD-WM-SARR-004, Rev. 1, Westinghouse Hanford Company, Richland, Washington.

Vendor File 1, Recirculation Cooling Fans, Fan Engineering Company, VI No. 22525, Supp33, January 19, 1996.

WHC, 1994, Drawing Set 1, Drawings: H-2-131088, sheets 1-4, H-2-131086, sheets 1-4, H-2-131087, sheets 1-2, Westinghouse Hanford Company.

Wood, S. A., 1993, FATHOMS Simulation of the September 3, 1992, Tank 101-SY GRE, (internal letter 23230-93-SAW-001 to G. D. Johnson, January 12), Westinghouse Hanford Company, Richland, Washington. 
WHC-SD-WIM-ER-592, Rev. 0

APPENDIX A. LETTER REPORT 23230-93-SAW-001. 
From: Waste Characterization Analys is

23230-93-SAW-001

Phone: $6-8658$ HO-34

Date: January 12, 1993

Subject: FATHOMS SIMULATION OF THE SEPTEMBER 3, 1992, TANK 101-SY GRE

To:

G. D. Johnson

$\begin{array}{ll}\text { CC: R. T. Allemann } & K 7-15 \\ \text { T. M. Burke } & H 0-34 \\ \text { S. C. Chang } & H 0-34 \\ \text { W. L. CowTey } & H 5-31 \\ \text { L. E. Efferding } & H 0-33 \\ \text { J. C. Fulton } & \text { R2-31 } \\ \text { J. M. Grigsby } & H 5-32 \\ \text { N. W. Kirch } & \text { R2-11 } \\ \text { W. L. Knecht } & H 0-34 \\ \text { M. R. Kreiter } & \text { K7-90 } \\ \text { J. W. Lentsch } & \text { R2-78 }\end{array}$

R2-78
K7-15
HO- 34

R. M. Marusich

T. B. MeCall

N. G. MeDuffie

M. D. Northey

D. M. Ogden

D. A. Reynolds

K. Sathyanarayana

L. K. Severud

SAW'File/LB:

Reference: Internal Memo, S. A. Wood to Distribution, "Estimate of the September 1992, GAS RELEASE VOLUME IN TANK 101-SY," dated September $28,19: 2$.

The FATHOMS ${ }^{2}$ code was used to simulate the September 3, 1992, Gas ReTease Event (GRE) which occurred in Tank 101-SY. Problems in interpreting the measured tank gas pressure have delayed issuing this memo, and have prevented arriving at any definitive estimates for the volume of gas released. Attempts at resolving the apparently anomalous pressure data have been partially successful. The range of estimated released gas volume based on the current FATHOMS results 7 ies between 6,000 and 15,000 cubic feet, with a probable value of about 10,000 cubic feet.

Attached is a discussion of the FATHOMS analysis results.

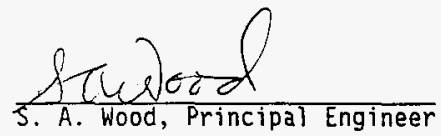

WLK

Attachment

CONCURRENCE:

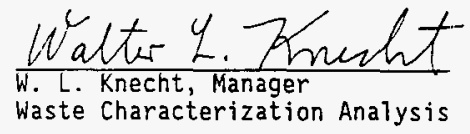

2FATHOMS is a reqistered trademark of Numerical Applications, Inc. 
WHC-SD-WM-ER-592, Rev. 0

Attachment

Page 1 of 16

FATHOMS SIMULATION OF THE SEPTEMBER 3, 1992, TANK 101-SY GRE

\section{BACKGROUND}

On September 3, 1992, a Gas Release Event (GRE) occurred in Tank 101-SY at about 2:40 p.m. Measured data became available by the following afternoon, and was input into the FATHOMS code in an attempt to estimate the volume of gas released during the GRE. When these results seemed inconsistent with both the measured pressure increase and the tank waste surface level change, an alternate procedure using only measured data was employed. An Internal Memo was issued with the alternate estimate of 8,400 cubic feet of gas released (reference). This report is to present the status of additional FATHOMS analyses made in an attempt to resolve the inconsistencies.

\section{FATHOMS MODEL}

All the FATHOMS calculations described in this report employed the same lumped parameter model as had been used in all previous Tank 101-SY GRE simulations. The only changes were the measured tank gas pressure and surface level changes as a function of time which are used as input for the FATHOMS analysis. This data is obtained directly from computer workstations located in the 200 Area where data obtained from the Tank 101-SY data loggers is stored.

Data input preparation for the FATHOMS analyses consists of converting the measured tank gas pressure (in inches wg) into absolute pressure (PSIA), and then dividing by the pre-release tank pressure to obtain relative pressure change as a function of time. For the initial FATHOMS calculations, tank surface level data from the radar gauge was used. Subsequent evaluation of the radar gauge has called into question the accuracy of its results. Hence, a 11 subsequent FATHOMS arialyses have used FIC level data. Since FATHOMS cannot dynamicaliy change a solid surface level, tank level changes have been modeled by including a pool of water at the bottom of the model's gas space, and then causing flow in or out of this pool so as to match the measured tank surface level chariges. The measured level data is therefore converted into a flow rate as a function of time in order to simulate the measured level changes.

The FATHOMS calculated tank gas pressure and surface level are compared to the measured data to verify that the input was correctly prepared.

\section{FATHOMS RESULTS}

Figure 1 presents the measured surface level in Tank 101 -SY during the GRE period which was used for part of the FATHOMS input as explained above. This data was obtained with the FIC gauge operated in a manual mode. Figure 2 shows the Tank 101-SY glas space pressure as measured by the exhaust duct pressure detector. The time period for this plot begins at midnight on September 1, two days before the gas release, and continues through noon on September 4 , the day after the release. The additional time period is included to show the pressure changes in the tank which occur on a daily basis, and appear related to changes in atmospheric temperature. If an even wider time period were chosen, tank pressure changes due to more gradual changes in atmospheric pressure could also be observed. This information is given to illustrate some of the difficulties in isolating pressure changes 
due to gas release from changes which appear to be unrelated to gas releases. The vertical axis scale for Figure 2 was chosen to better display the daily pressure variations, but does not show the peak tank pressure, which was recorded as +5.4 inches wg. The surface level data in Figure 1 do not show any indication of significant gas releases from September 1 to the afternoon of September 3 . The FATHOMS code model explicitly assumes that pressures in the tank above the pre-release value is due to gas release, so any pressure changes unrelated to gas release has to be removed from the data prior to use with the code. From Figure 2, it appears that the pressure changes on September 3 prior to the sharp increase in pressure is part of the daily variation, and that pressure changes due to the GRE are superimposed on top of the daily variation.

Figure 3 is an expanded scale plot of the tank gas space pressure, beginning at noon and continuing to midnight on September 3 . In order to remove some of the uncertainty associated with using data from a single instrument, pressure data from the Gas Monitoring System (GMS) detector is also shown. Both sets of pressure data show essentially the same response--a sharp pressure rise at about 2:40 p.m. starting from about -2.35 inches wg, a corresponding quick pressure decrease to about -2.15 inches $w g$, followed by a gradual decrease which reaches the pre-release pressure at about $6: 20 \mathrm{p} . \mathrm{m}$. Initial FATHOMS calculations were made using just the pressure changes between 2:00 p.m. and 6:00 p.m. which were believed due to released gas, plus the surface level changes shown in Figure 1.

Results from this initial calculation are shown in Figures 4 and 5 . Figure 4 presents the FATHOMS predicted gas space hydrogen concentration which assumes perfect mixing, and which peaks at about $3.9 \%$. The relatively flat top of the curve is due to gas release predicted by the code during the long slow pressure change period described above. Cumulative gas release versus time is shown in Figure 5. Careful examination of this data indicates that these results are composed of three components. The first, showing a rapid increase to about 6,000 cubic feet, is due to the initial sharp increase in pressure and the rapid drop in surface level. The second component, increasing the volume from 6,000 to about 10,000 cubic feet, is due primarily to the continuing surface level decrease which the FATHOMS code translates into gas release. The final component of the calculated release volume, increasing the volume from 10,000 to about 15,000 cubic feet, is primarily due to the slightly elevated tank pressure which persists until about $6: 00 \mathrm{p} . \mathrm{m}$., the same time that the calculated release volume increase terminates. Other sources have estimated release volumes of about 10,000 cubic feet, so it is important to verify the validity of the four hour sightly elevated tank pressure to determine if this additional volume is valid.

The usual technique used to verify the accuracy of the FATHOMS calculations is to compare measured/calculated values for hydrogen concentration and exhaust flow rate. Figure 6 shows measured hydrogen concentration data from the two Whitaker detectors located about 18 inches above the waste surface. Usually data from the Teledyne detector which measures hydrogen concentrations in the exhaust duct is used since it better represents mixed tank conditions calculated by FATHOMS. Unfortunately, the Teledyne data was useless for this release due to a problem with this system. However, data from the May 1992 GRE in Tank 10:-SY showed that the Teledyne and Whitaker data were essentially the same, indicating good mixing and/or uniformity of gas release. Thus, there is reasonable validity in comparing whitaker data 
and FATHOMS predictions of hydrogen concentration. Comparison between measured and FATHOMS calculated nydrogen concentrations for previous GRE's have been quite good, usually agreeing within a few tenths of a percent. However, for this reiease the peak measured concentration was about $4.9 \%$ and the corresponding FATHOMS value was only $3.9 \%$. The shape of the two curves don't agree very well either, with the FATHOMS data implying more release after the initial peak which is consistent with questions about the estimated release gas volume.

Figure 7 is the measured high range exhaust flow, and Figure 8 is the FATHOMS calculated exhaust flow. It is clear that FATHOMS is underpredicting the peak exhaust flow. This peak flow is directly defined by the peak tank pressure input for the analysis. It therefore appears that the measured tank pressure recorded on the data loggers is too low, which would a) so explain why the FATHOMS peak hydrogen concentration is too low. Figure 9 is an expanded scale plot of the measured exhaust flow, and Figure 10 is the FATHOMS calculated exhaust flow on the same scale. Picking precise values of flow from the measured data is difficult due to the rapid variations in the data, but it is clear that the measured exhaust flow returns to pre-release values by about 3:30 p.m., implying that the release has terminated by then. However, because of the slightly elevated pressure data used for the input, the FATHOMS calculated flow remains high for the entire time period. This strongly implies that the slightly elevated pressure after the main part of the release was due to something not related to gas release.

In an attempt to determine the sensitivity of the FATHOMS results to post peak release tank pressure input, a run was made using pressure data input that was arbitrarily truncated inmediately after the peak. Figure 11 shows a 30 minute slice of the pressure data around the peak. The heavy dotted line is the modified pressure values. Figure 12 is the FATHOMS calculated hydrogen concentration for the modified pressure input. The peak value is too low as expected, but the shape appears closer to the measured data in Figure 6 . The calculated release volume in Figure 13 indicates that the truncation was too abrupt, causing an under-prediction of the volume. This sensitivity calculation was not intended to provide a definitive answer, but does lend support to the contention that the four hour elevation in the pressure data after the release was not due to gas release.

\section{CONCLUSION}

Difficulties in determining what part of the pressure increases in Tank 101-SY during the September 3, 1992, GRE were due to released gas have caused a large uncertainty in the FATHOMS simulation of the event. The best that can be said about estimated-gas-release-volume is that a value of about 10,000 cubic feet seems reasonable. 
WHC-SD-WM-ER-592, Rev. 0

Figure 1. Tank 241-SY-101 Surface Levels.

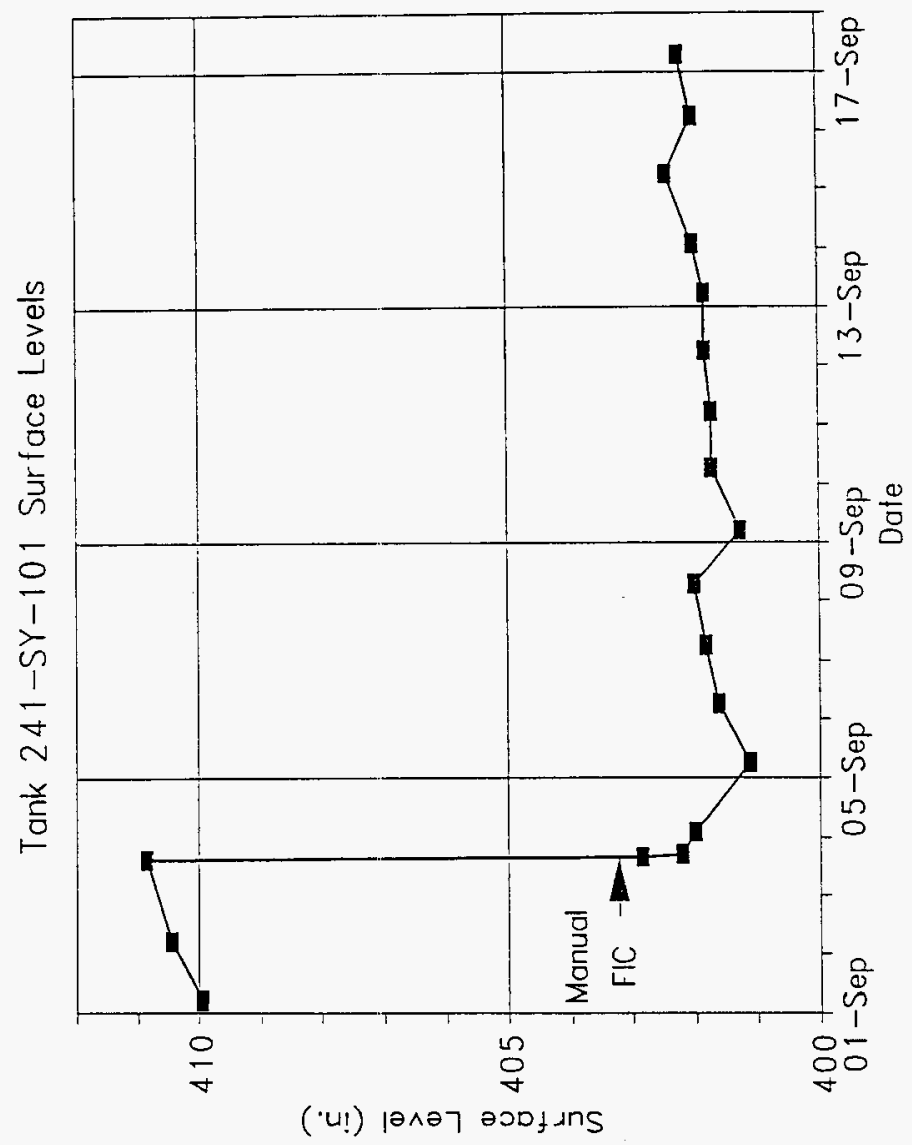


Figure 2. Measured Tank 101-ST Data

Tank Pressure for September 3, 1992.

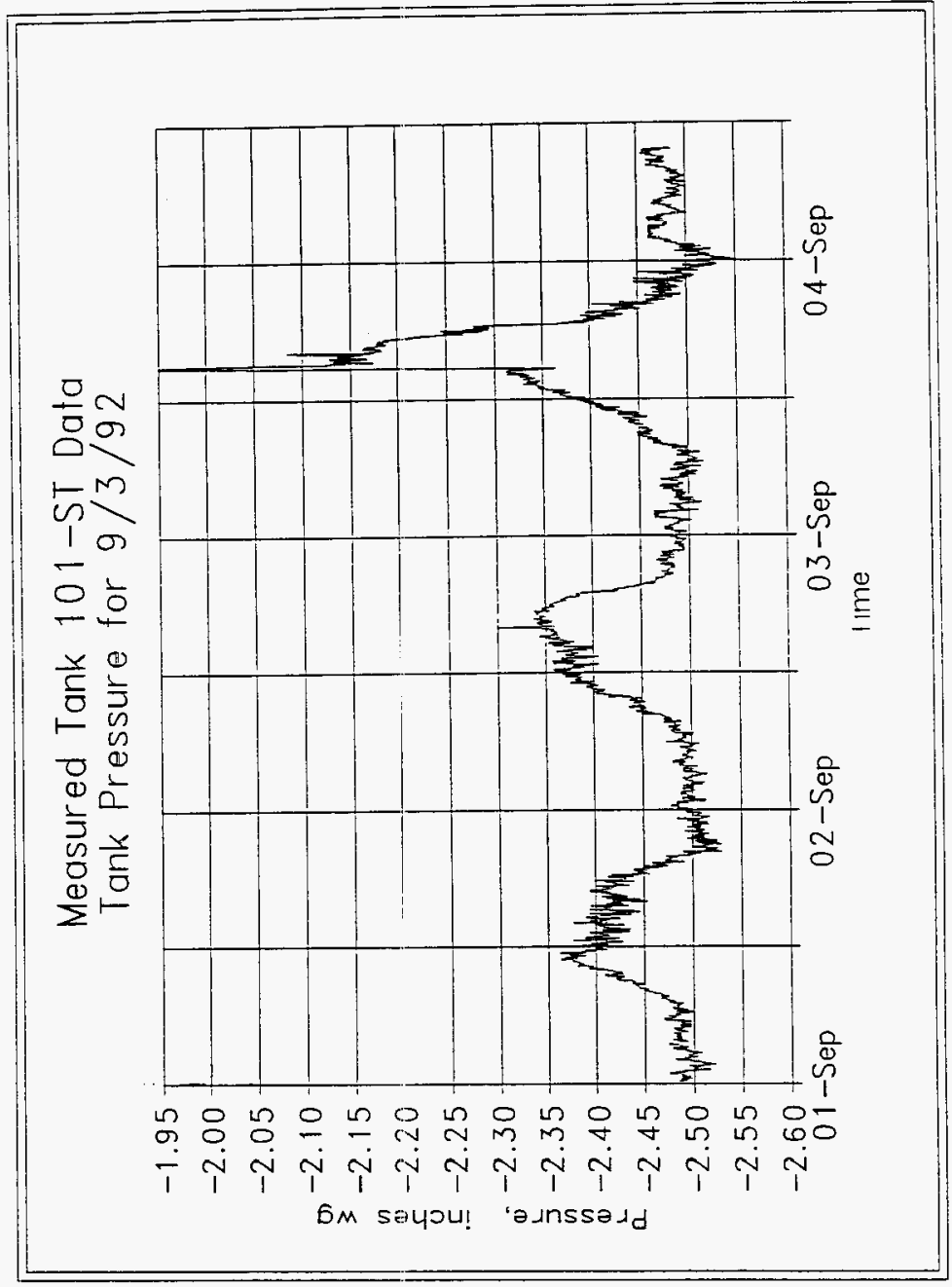




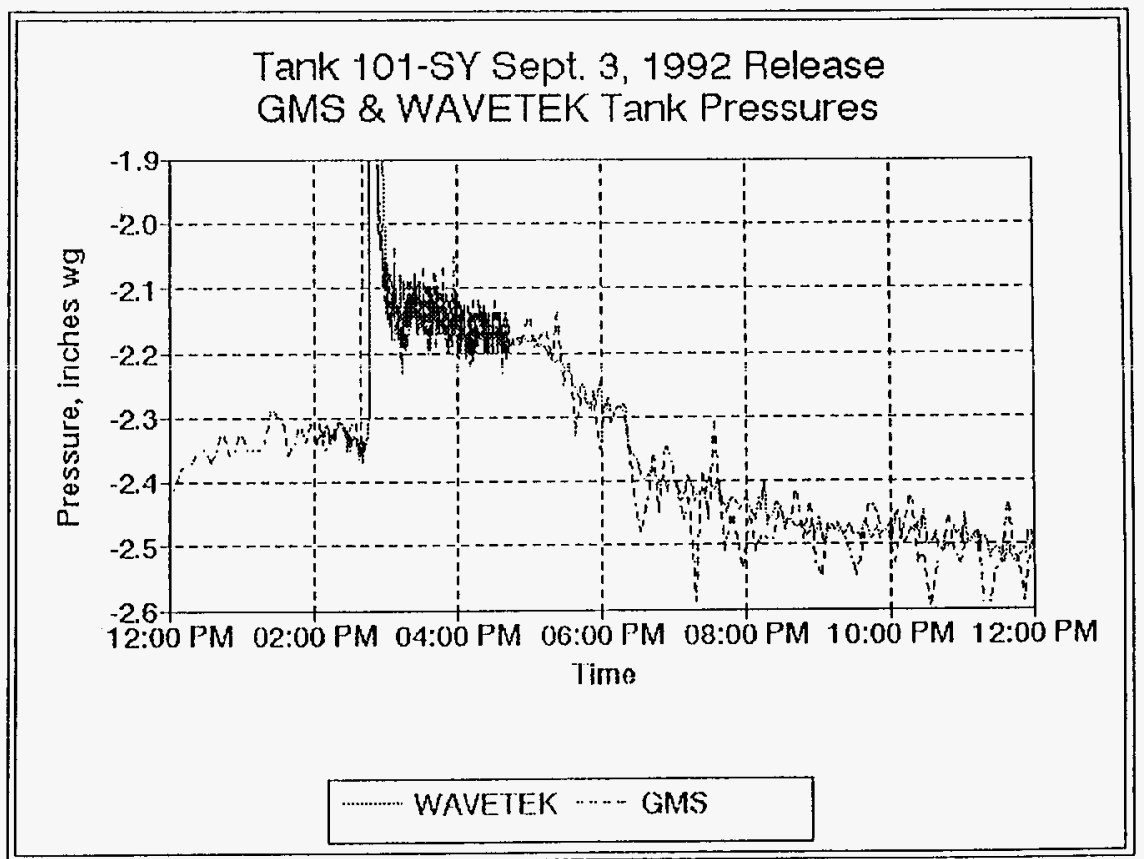


WHC-SD-WM-ER-592, Rev. 0

Figure 4. FATHONS Results for September 3, 1992, GRE Gas Space Hydrogen Concentration.

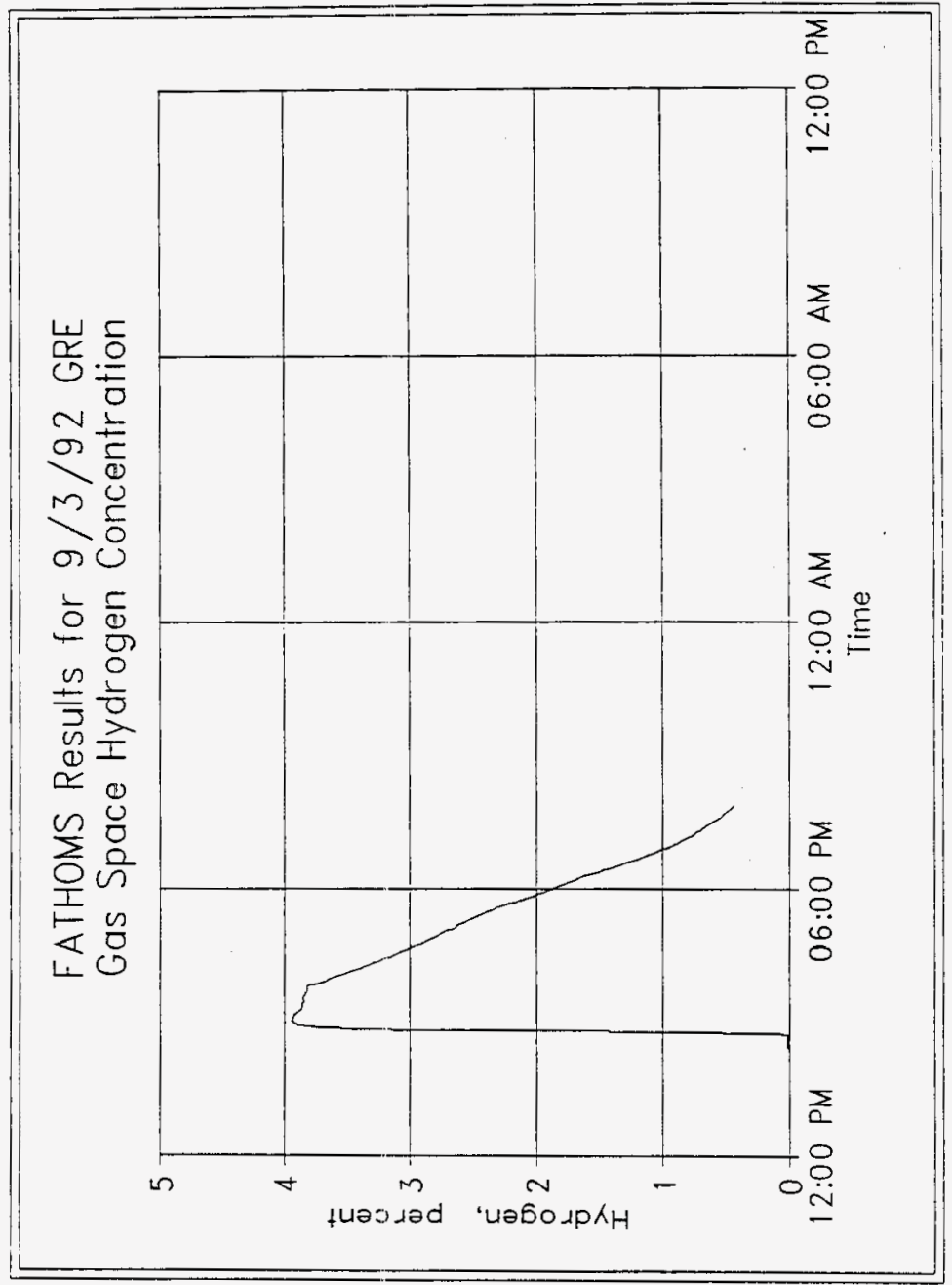


WHC-SD-WMM-ER-592, Rev. 0

Figure 5. FATHOMS Results for September 3, 1992, GRE Gas Release Volume.

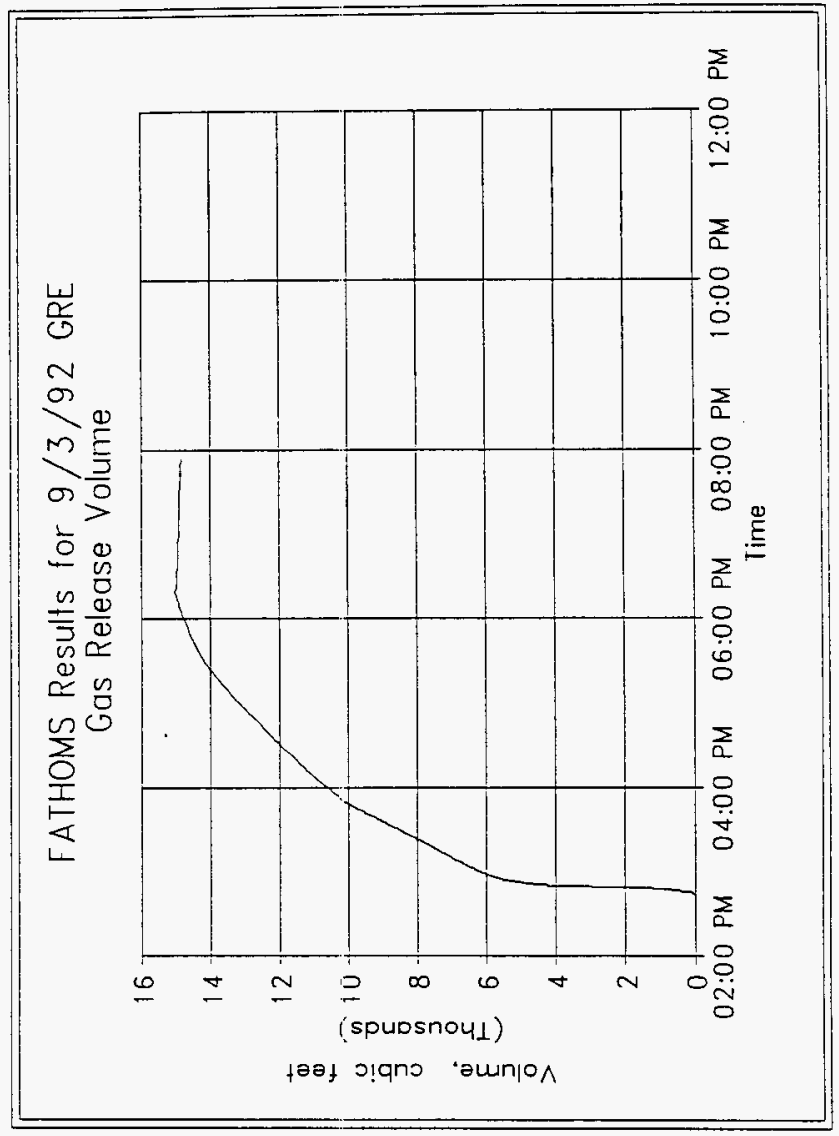


Figure 6. Tank 101-sY September 3, 1992, Release Whitaker Hydrogen Concentration.

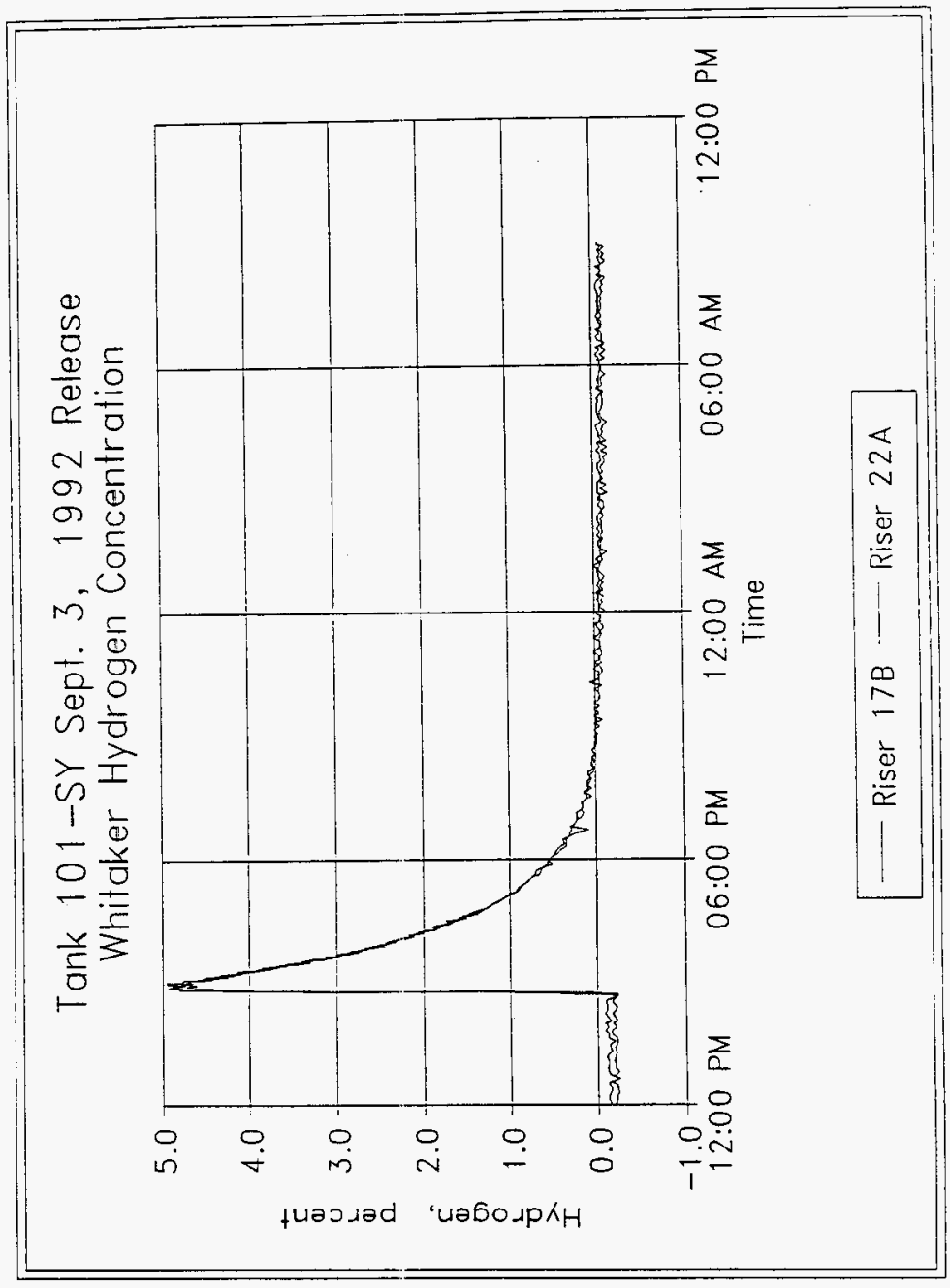


Figure 7. Tank 101-5Y September 3, 1992, Release Wavetek Highı Range Exhaust Flow.

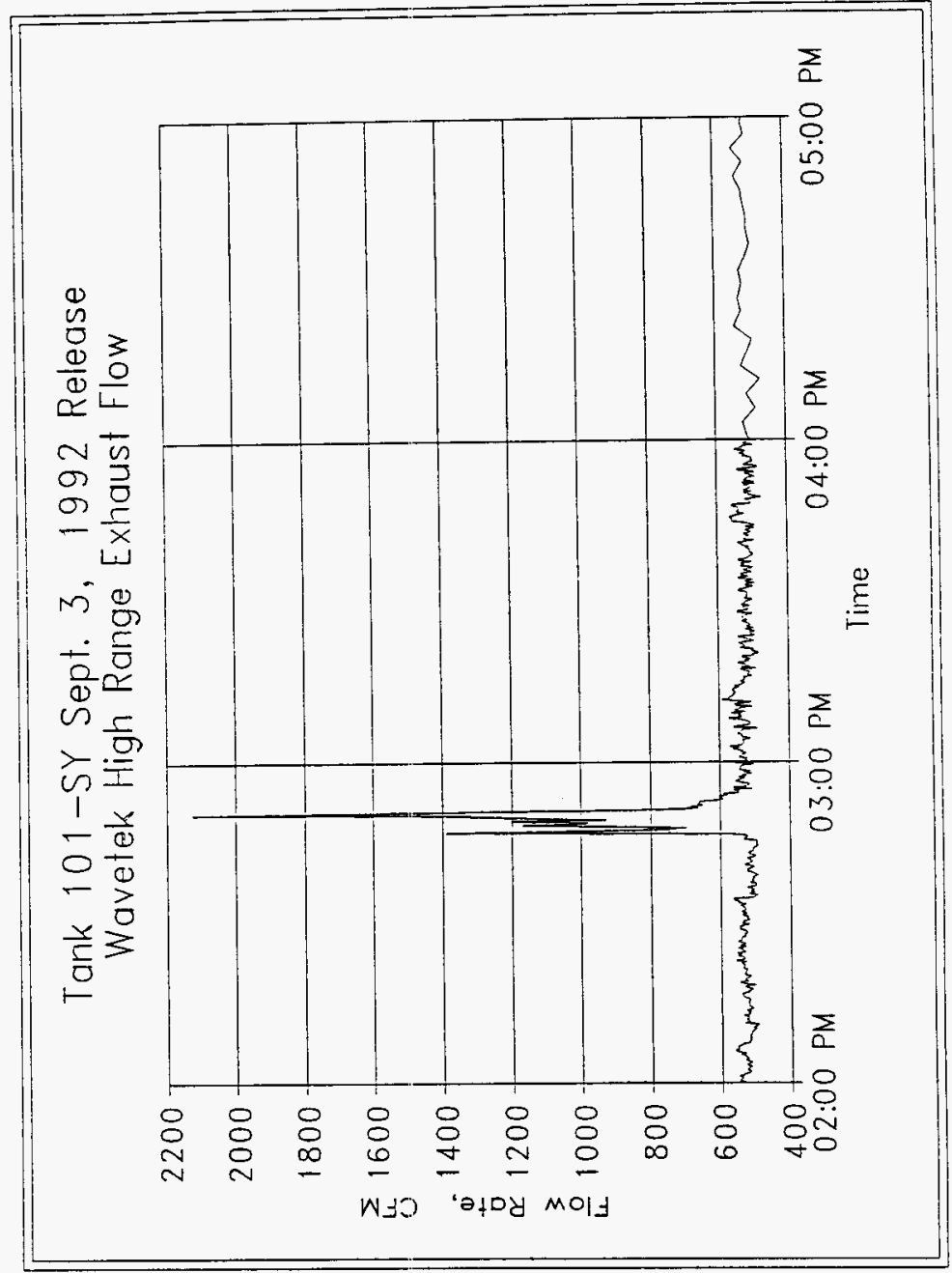


WHC-SD-HM-ER-592, Rev. 0

Figure 8. FATHOMS Results for September 3, 1992, GRE Exhaust Gas flow.

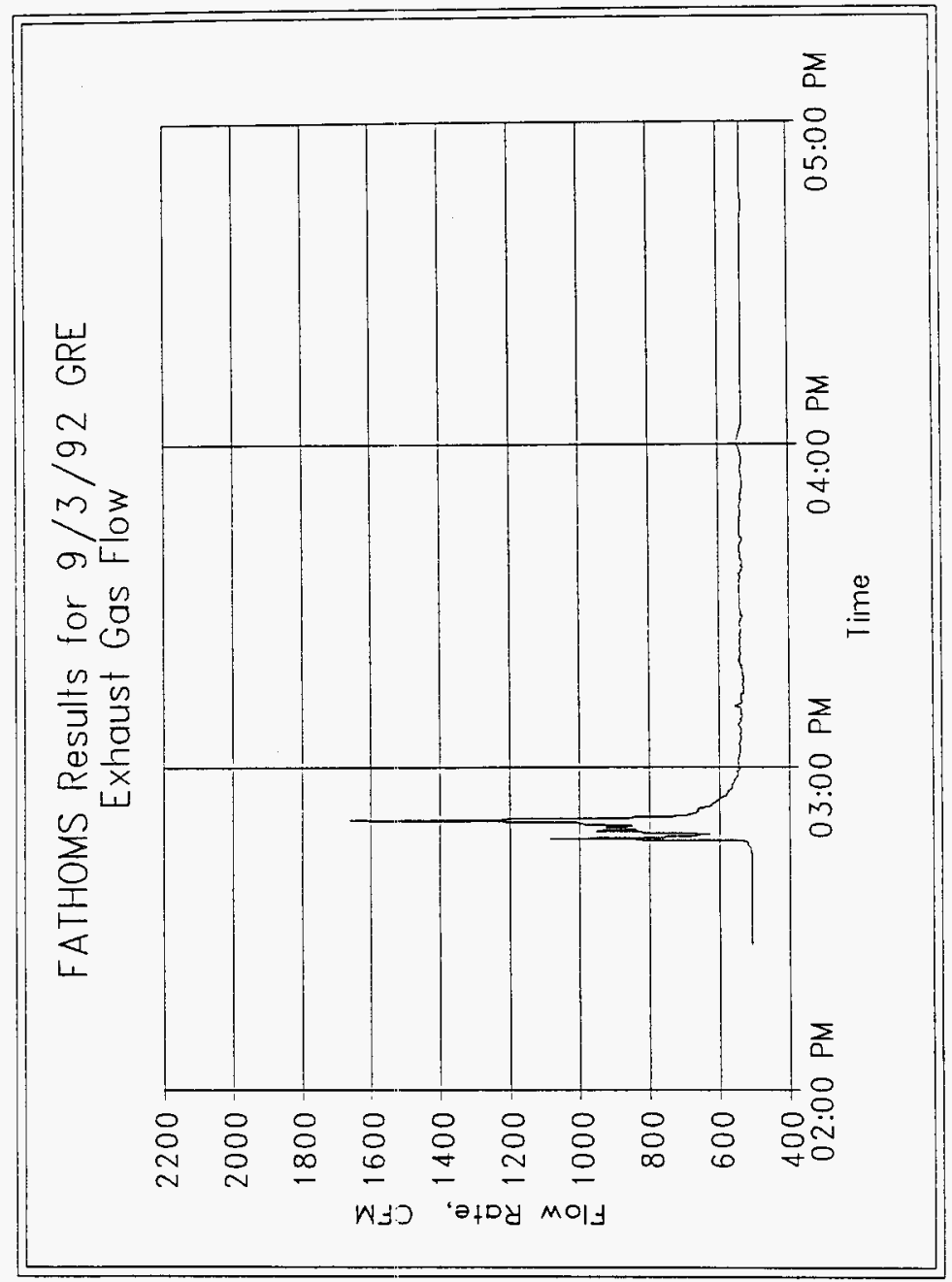


Figure 9. Tank 101-SY September 3, 1992, Release Wavetek High Range Exhaust Flow.

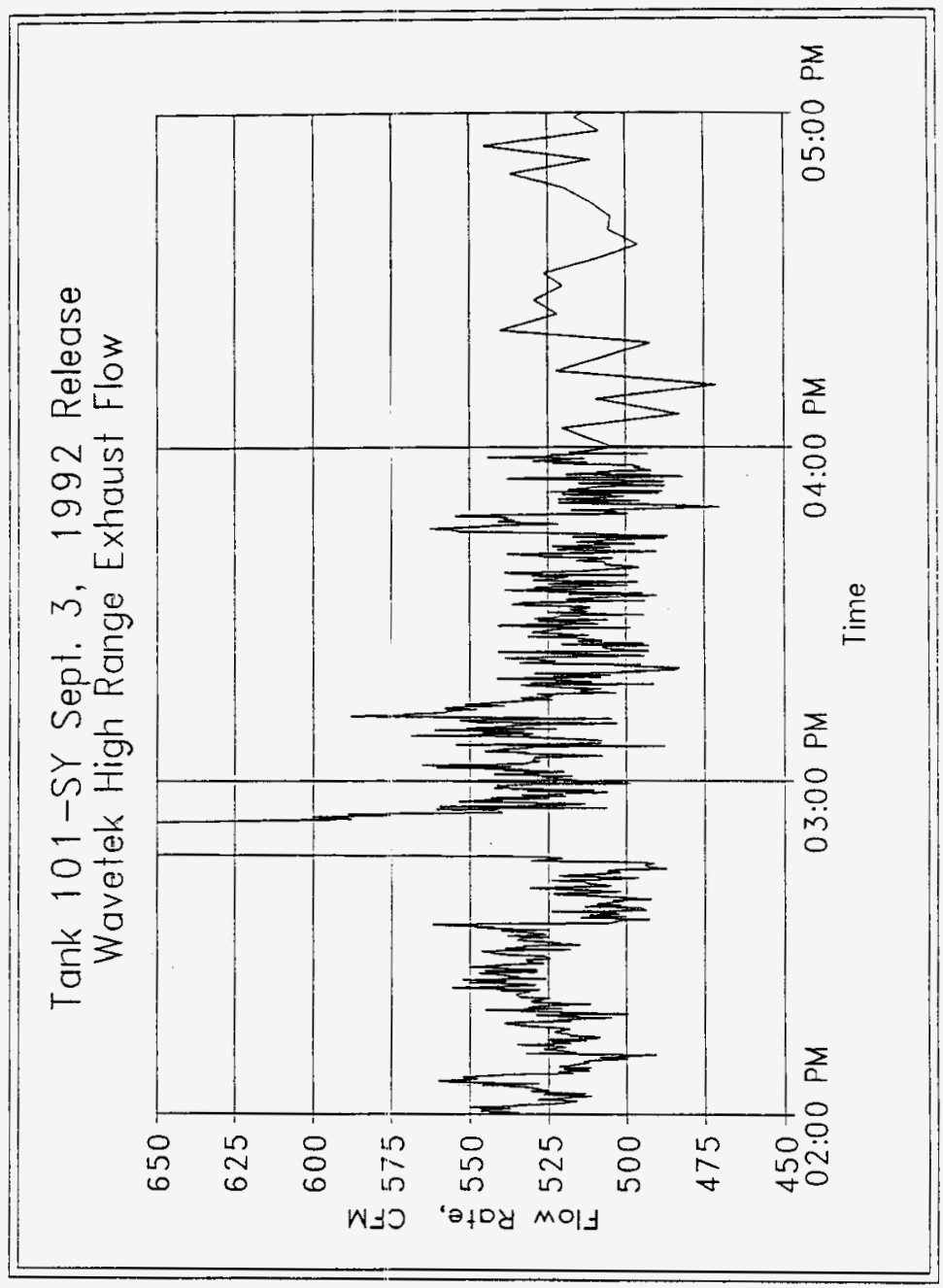


Figure 10. FATHOMS Results for September 3, 1992, GRE Exhaust Gas Flow

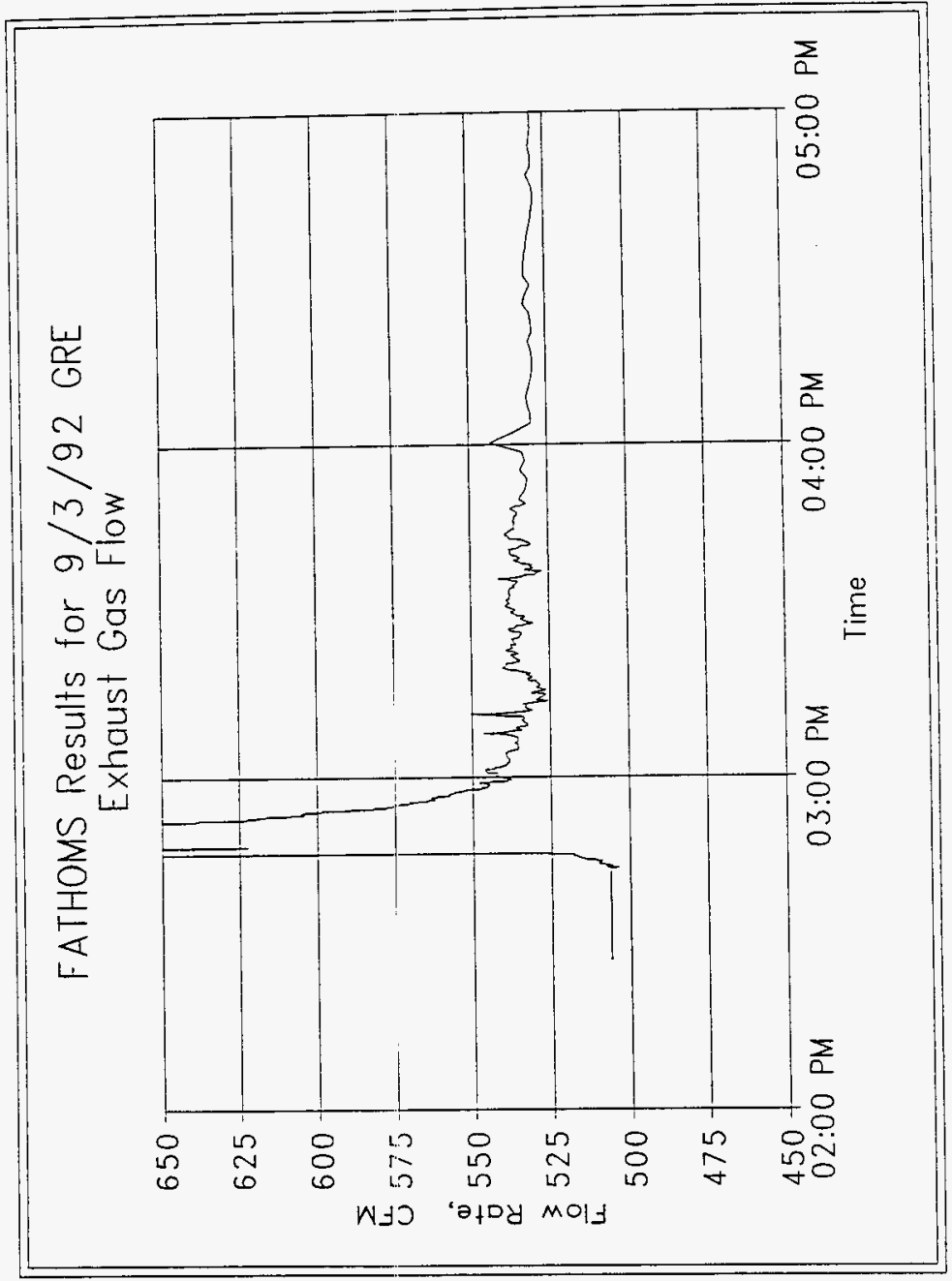


WHC-SD-MM-ER-592, Rev. 0

Figure 11. Tank 101-SY September 3, 1992, Release Wavetek Tank Pressure.

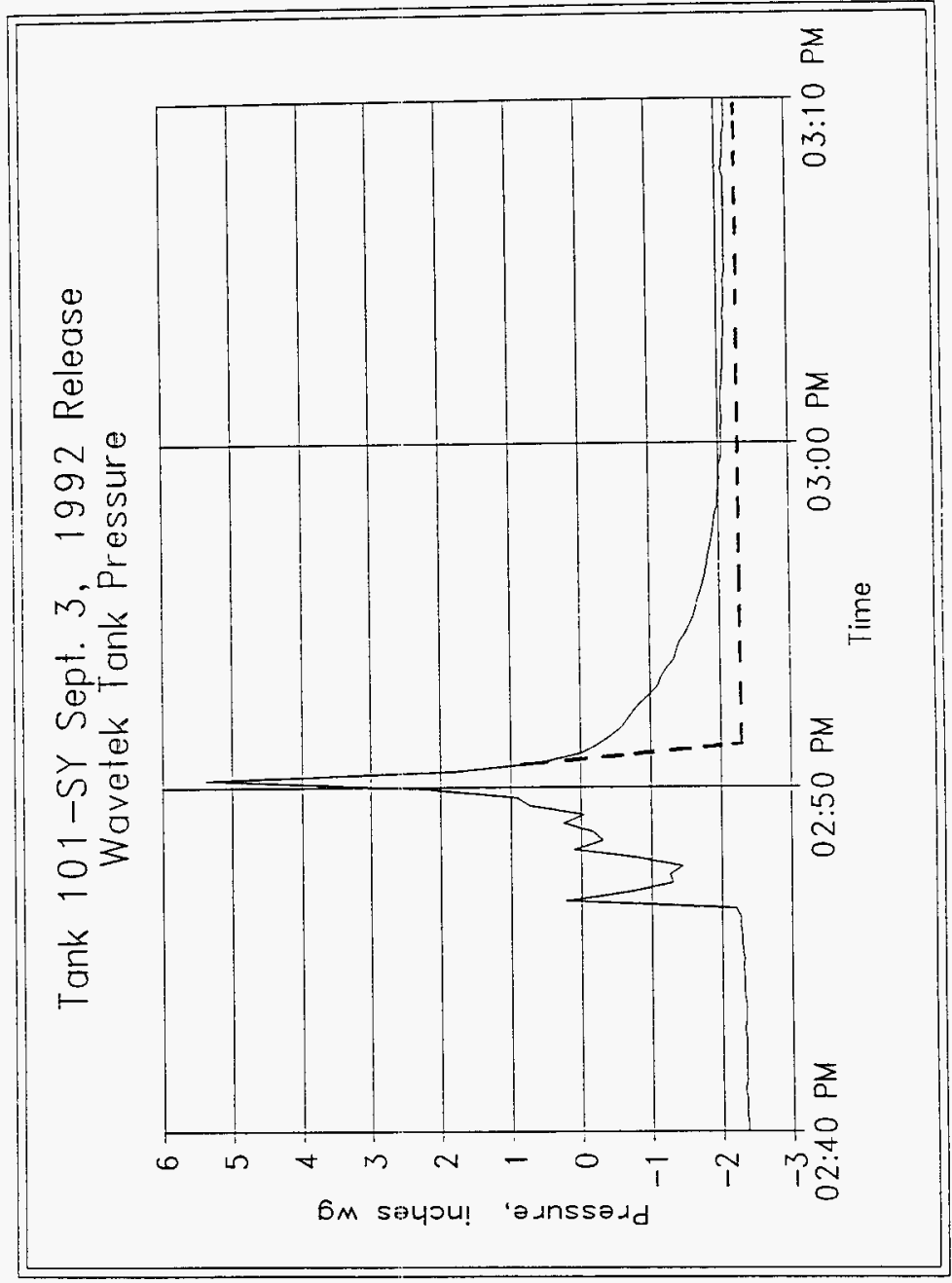


9/3/92 GRE Tank 101-SY FATHOMS Results Gas Space Hydrogen Concentration
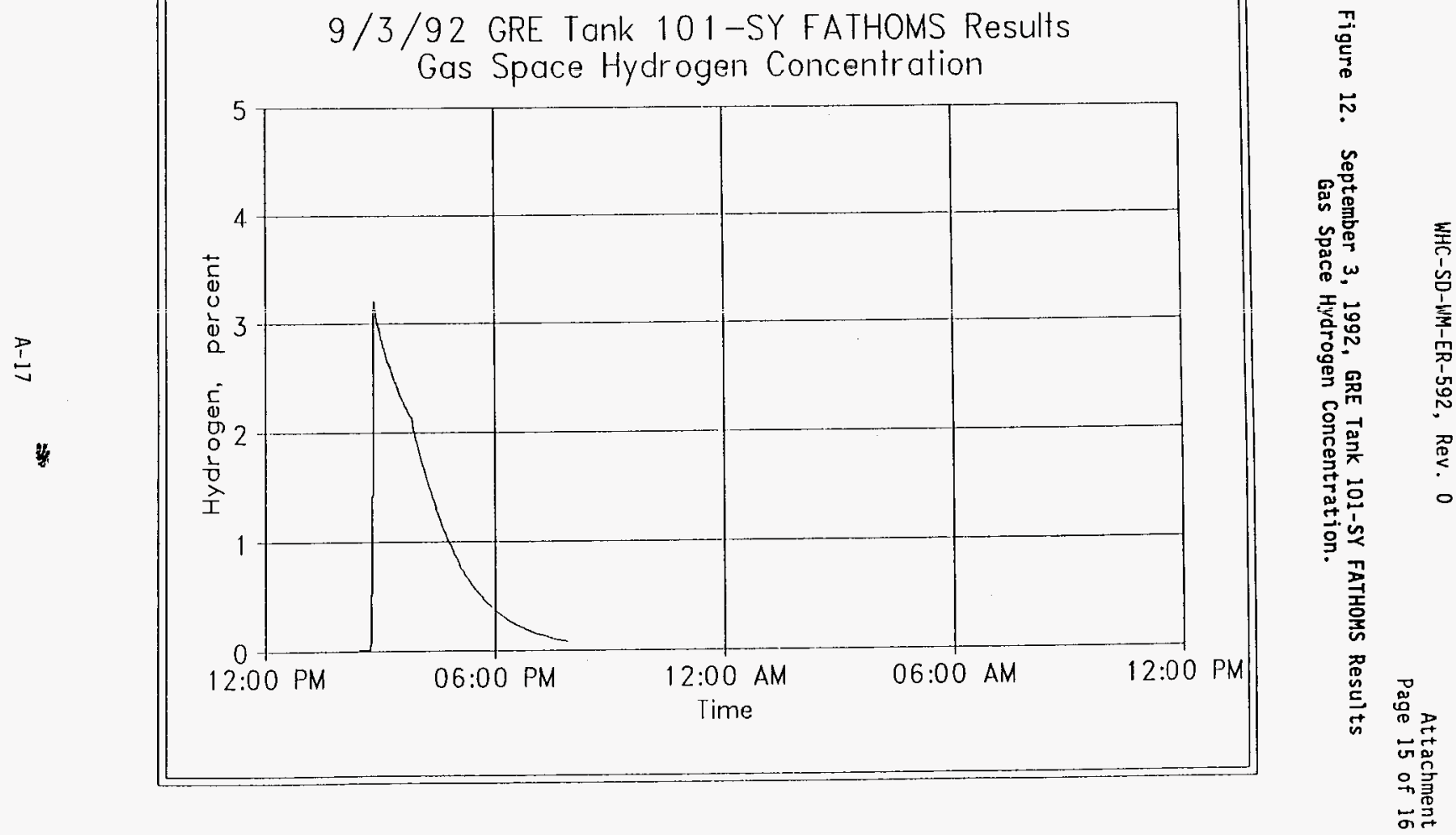
WHC-SD-WM-ER-592, Rev. 0

Attachment

Page 16 of 16

Figure 13. FATHOMS Results for September 3, 1992, GRE Gas Fielease Volume.

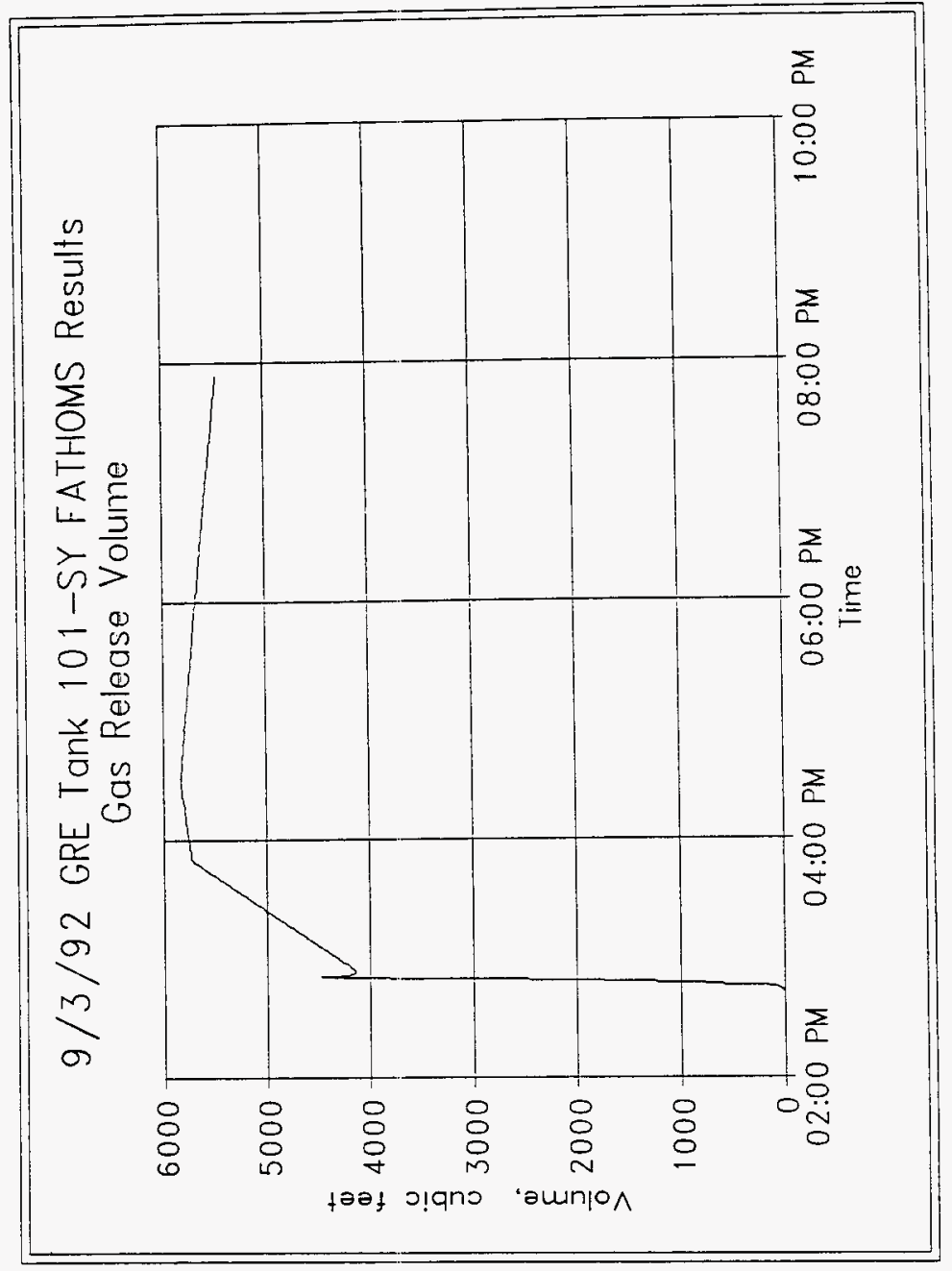


DISTRIBUTION SHEET

\begin{tabular}{|c|c|c|c|c|c|}
\hline \multirow{2}{*}{$\begin{array}{l}\text { To } \\
\text { Distribution }\end{array}$} & \multirow{2}{*}{\multicolumn{3}{|c|}{\begin{tabular}{|l} 
From \\
Process Engineering Analysis
\end{tabular}}} & \multicolumn{2}{|l|}{ Page 1 of 1} \\
\hline & & & & \multicolumn{2}{|c|}{ Date August 1, 1996} \\
\hline \multirow{2}{*}{\multicolumn{4}{|c|}{$\begin{array}{l}\text { Project Title } / \text { Work Order } \\
W-030 / N B 602\end{array}$}} & \multicolumn{2}{|c|}{ EDT No. $\quad 614686$} \\
\hline & & & & \multicolumn{2}{|l|}{ ECN No. N/A } \\
\hline Name & MSIN & $\begin{array}{l}\text { Text } \\
\text { With All } \\
\text { Attach. }\end{array}$ & Text Only & $\begin{array}{l}\text { Attach./ } \\
\text { Appendix } \\
\text { Only }\end{array}$ & $\begin{array}{c}\text { EDT/ECN } \\
\text { Only }\end{array}$ \\
\hline $\begin{array}{l}\text { K. A. Colosi } \\
\text { J. C. Conner } \\
\text { D. S. Conningham } \\
\text { J. L. Deichman } \\
\text { B. C. Fryer } \\
\text { J. E. Gould } \\
\text { R. L. Guthrie } \\
\text { G. N. Hanson } \\
\text { M. D. Harding } \\
\text { J. J. Klos } \\
\text { J. R. Kriskovich } \\
\text { C. E. Leach } \\
\text { D. R. Leach } \\
\text { R. M. Marusich } \\
\text { N. J. Milliken } \\
\text { D. M. Ogden } \\
\text { S. H. Rifaey } \\
\text { J. P. Sloughter } \\
\text { S. M. Stah1 } \\
\text { G. R. Tardiff } \\
\text { M. J. Thurgood } \\
\text { J. A. Upshaw } \\
\text { R. J. Van Vleet } \\
\text { Central Files (Original + 1) } \\
\text { PEA File (Burstad 6) }\end{array}$ & $\begin{array}{l}\text { R3-25 } \\
\text { A2-25 } \\
\text { TO-06 } \\
\text { R3-08 } \\
\text { HO-34 } \\
\text { H6-26 } \\
\text { A3-37 } \\
\text { S5-05 } \\
\text { S5-10 } \\
\text { R2-54 } \\
\text { S2-24 } \\
\text { A2-34 } \\
\text { A3-34 } \\
\text { A3-34 } \\
\text { A3-37 } \\
\text { H0-34 } \\
\text { R1-56 } \\
\text { R2-54 } \\
\text { A3-37 } \\
\text { S5-05 } \\
\text { H0-34 } \\
\text { B1-12 } \\
\text { A3-34 } \\
\text { A3-88 } \\
\text { HO-34 }\end{array}$ & $\begin{array}{l}x \\
x \\
x \\
x \\
x \\
x \\
x \\
x \\
x \\
x \\
x \\
x \\
x \\
x \\
x \\
x \\
x \\
x \\
x \\
x \\
x \\
x \\
x \\
x \\
x\end{array}$ & & & \\
\hline
\end{tabular}

